2014s-30

\title{
Informational Asymmetries in Laboratory Asset Markets with State-Dependent Fundamentals
}

\author{
Claudia Keser, Andreas Markstädter
}

Série Scientifique
Scientific Series

\author{
Montréal \\ Mai/May 2014
}

(C) 2014 Claudia Keser, Andreas Markstädter. Tous droits réservés. All rights reserved. Reproduction partielle permise avec citation du document source, incluant la notice $($.

Short sections may be quoted without explicit permission, if full credit, including (C) notice, is given to the source.
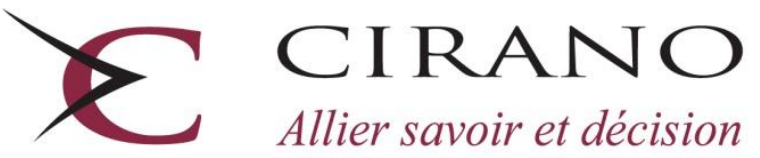

Allier savoir et décision

Centre interuniversitaire de recherche en analyse des organisations 


\section{CIRANO}

Le CIRANO est un organisme sans but lucratif constitué en vertu de la Loi des compagnies du Québec. Le financement de son infrastructure et de ses activités de recherche provient des cotisations de ses organisations-membres, d'une subvention d'infrastructure du Ministère de l'Enseignement supérieur, de la Recherche, de la Science et de la Technologie, de même que des subventions et mandats obtenus par ses équipes de recherche.

CIRANO is a private non-profit organization incorporated under the Québec Companies Act. Its infrastructure and research activities are funded through fees paid by member organizations, an infrastructure grant from the Ministère de l'Enseignement supérieur, de la Recherche, de la Science et de la Technologie, and grants and research mandates obtained by its research teams.

\section{Les partenaires du CIRANO}

\section{Partenaire majeur}

Ministère de l'Enseignement supérieur, de la Recherche, de la Science et de la Technologie

\section{Partenaires corporatifs}

Autorité des marchés financiers

Banque de développement du Canada

Banque du Canada

Banque Laurentienne du Canada

Banque Nationale du Canada

Banque Scotia

Bell Canada

BMO Groupe financier

Caisse de dépôt et placement du Québec

Fédération des caisses Desjardins du Québec

Financière Sun Life, Québec

Gaz Métro

Hydro-Québec

Industrie Canada

Intact

Investissements PSP

Ministère des Finances et de l'Économie

Power Corporation du Canada

Rio Tinto Alcan

Transat A.T.

Ville de Montréal

\section{Partenaires universitaires}

École Polytechnique de Montréal

École de technologie supérieure (ÉTS)

HEC Montréal

Institut national de la recherche scientifique (INRS)

McGill University

Université Concordia

Université de Montréal

Université de Sherbrooke

Université du Québec

Université du Québec à Montréal

Université Laval

Le CIRANO collabore avec de nombreux centres et chaires de recherche universitaires dont on peut consulter la liste sur son site web.

Les cahiers de la série scientifique (CS) visent à rendre accessibles des résultats de recherche effectuée au CIRANO afin de susciter échanges et commentaires. Ces cahiers sont écrits dans le style des publications scientifiques. Les idées et les opinions émises sont sous l'unique responsabilité des auteurs et ne représentent pas nécessairement les positions du CIRANO ou de ses partenaires.

This paper presents research carried out at CIRANO and aims at encouraging discussion and comment. The observations and viewpoints expressed are the sole responsibility of the authors. They do not necessarily represent positions of CIRANO or its partners. 


\title{
Informational Asymmetries in Laboratory Asset Markets with State-Dependent Fundamentals
}

\author{
Claudia Keser ${ }^{*}$, Andreas Markstädter ${ }^{*}$
}

\section{Résumé/abstract}

We investigate the formation of market prices in a new experimental setting involving multi-period call-auction asset markets with state-dependent fundamentals. We are particularly interested in two informational aspects: (1) the role of traders who are informed about the true state and/or (2) the impact of the provision of Bayesian updates of the assets' state-dependent fundamental values (BFVs) to all traders. We find that bubbles are a rare phenomenon in all of our treatments. Markets with asymmetrically informed traders exhibit smaller price deviations from fundamentals than markets without informed traders. The provision of BFVs has little to no effect. Behavior of informed and uninformed traders differs in early periods but converges over time. On average, uninformed traders offer lower (higher) limit prices and hold less (more) assets than informed traders in "good"-state ("bad"-state) markets. Informed traders earn superior profits.

Mots clés/keywords : Experimental economics, asset markets, informational asymmetries

Codes JEL : C92, D47, D53, D82, G14

\footnotetext{
* Corresponding author: Chair of Microeconomics, Faculty of Economic Sciences, Georg-August-Universität Göttingen, E-mail: claudia.keser@uni-goettingen.de; Tel.: +49 (0) 551 - 398040

${ }^{\dagger}$ Chair of Microeconomics, Faculty of Economic Sciences, Georg-August-Universität Göttingen, E-mail: andreas.markstaedter@uni-goettingen.de; Tel. +49(0)551 - 394680
} 


\section{Introduction}

Financial markets are characterized by pronounced informational asymmetries. This is particularly true in times of market uncertainty, for example, following economic turbulences or in the wake of stock market launches (IPOs). In order that markets can perform their allocative function under this premise, market prices should reflect all available information. In other words, markets have to be informationally efficient. Assuming market participants to use all available public and private information, the transfer of information considerably influences allocative market efficiency (Leland and Pyle 1977). It is thus crucial to understand to what extent information is revealed through market prices. Ultimately, market prices should be consistent with rational expectations (as defined by Muth 1961) about future benefits and not be driven by informational "mirages" 1 , speculation or the lack of proper investment alternatives.

With respect to these issues regarding informational asymmetries, the potential influence that insider trading exerts on market prices, unmonitored by financial market authorities, is of particular interest. Apart the fact that unrestricted insider trading is prohibited by law in all prominent financial markets, it likely takes place. Interestingly, Bris (2005), using acquisition data from 52 countries between 1990 and 2000, finds that the introduction of laws that prohibit insider trading increases the occurrence and profitability of insider trading. Jeng et al. (2003), using Center for Research in Securities Prices (CRSP) transactions data from 1975 to 1996, find further that insider purchases yield returns that are more than $6 \%$ above expected returns per year, while insider sales do not yield significant abnormal returns. In the ongoing debate between proponents and opponents of deregulation of insider trading in the economic and law literature, to date, neither efficiency nor fairness and equity arguments can mutually persuade the debating parties (Fishman and Hagerty 1992, Bainbridge 1998).

In this paper, we study asset price formation in a new experimental setting involving multi-period assets in an environment with uncertainty about market fundamentals. Specifically, we consider the existence of two possible states of nature. We compare price formation in markets with and without informational asymmetry. In the latter markets, some of the traders do have information on the true state, while other traders don't. We use the experimental-economics laboratory as a wind channel to study whether financial markets are informationally efficient and how informational asymmetries (due to insider information) impact market price formation. This would hardly be possible (if not impossible) to disentangle on real market grounds, due to the blurry nature of underlying securities' values and the uncontrollable and incalculable information distribution among market participants in real-life markets. In the experiment we can control the information available to market participants and the

\footnotetext{
${ }^{1}$ Camerer and Weigelt (1991) define mirages in the following way: "[I]n inferring information from the trades of others, traders sometimes err and their errors cause others to overreact, creating price paths that falsely reveal information that no one has." (p. 489)
} 
securities' fundamentals. Although the expectation formation of market participants remains difficult to grasp, ${ }^{2}$ we can explicitly control the informational asymmetries between market participants, including the number of informed participants (henceforth also inside traders or insiders) relative to the uninformed (henceforth also outside traders or outsiders). We neither claim nor aim to resolve the debate between proponents and opponents of insider trading regulation, however, strive to fuel the discussion with the provision of additional experimental evidence.

Since the seminal paper by Smith et al. (1988) (henceforth, SSW) countless studies have investigated common stock valuation in experimental asset markets with multi-period assets characterized by declining fundamental values (FVs). However, relatively few studies consider informational asymmetries. If (experimental) markets are efficient, the market value should equal the risk-adjusted present value of the rationally expected future financial benefits conditioned on all available information. Asset price changes should only occur when new information is brought into the market, which changes expectations about the income stream (Shiller 2003). Deviations from fundamentals, if at all, should be only temporary until the risk-adjusted expectations converge. Such kind of markets would approximate what Fama (1970), the originator of the efficient-market hypothesis (EMH), called "efficient". However, SSW-type markets predominantly resist showing efficiency and persistently exhibit bubbles, which hardly can be explained by differences in preferences or risk aversion. The observed bubble-and-crash phenomenon is found to be strikingly robust to changes in the experimental environment. ${ }^{3}$ "Smart money" 4 seems not as smart as desired by theory in view of the numerously observed experimental (and real-life) bubbles. The only factor that fairly reliably impairs this widely observed pattern is experience (in the sense of repetition). Dufwenberg et al. (2005) have shown that even a fraction of experienced subjects in an experimental market is sufficient to reduce the occurrence of bubbles. However, this seems to hold only if the market environment (initial endowments and dividend structure) remains unchanged during the trials (Hussam et al. 2008).

On the basis of Dufwenberg et al. (2005), Sutter et al. (2012) hypothesize that, in addition to experience, an asymmetric distribution of information about an asset's imminent future dividends among the participants might serve to reduce mispricing, i.e., the magnitude of bubbles. They argue that the core of this alleviating effect might lie in the common knowledge of the existence of better informed or experienced traders.

\footnotetext{
${ }^{2}$ How the available information disseminates through the market and is processed by the individual traders to build individual expectations remains a tremendous source of uncertainty. It resembles Keynes (1936) view of the stock market as a "beauty contest" in which traders are more concerned about the beliefs of others than about their own valuation based upon all available information. As good as the experimenters can control for the market parameters, as bad they can control the endogenous beliefs of participants about other participants' behavior (Noussair and Plott 2008).

${ }^{3}$ See, e.g., King et al. (1993), Porter and Smith (1994), or Palan (2009) for comprehensive and salient reviews of the experimental "bubble" literature. For an overview of bubble definitions see, e.g., Siegel (2003).

4 "Smart money" theory as a branch of the efficient market hypothesis was considered to be able to keep prices tracking fundamentals (Shiller 2003).
} 
Implementing a SSW framework, they find information asymmetries to significantly reduce the size of price bubbles, implying higher market efficiency. Moreover, they do not detect a significant difference in profits between traders with different information levels. However, in an earlier study, King (1991) finds no evidence for asymmetric distribution of information to eliminate price bubbles in a SSW environment. In his study informed traders, likewise, could not capitalize their informational advantage through higher profits; they were just able to recoup the costs for the acquisition of the private information. ${ }^{5}$

Another experimental literature strand studies asymmetric information using an approach different from SSW. It is based on one-period Arrow-Debreu assets with statecontingent and trader-type dependent dividends, and in the cases where insider information is investigated, asymmetric distributions of state information (e.g., (Forsythe et al. 1982, Plott and Sunder 1982, Forsythe et al. 1984, Ang and Schwarz 1985, Plott and Sunder 1988, Camerer and Weigelt 1991, Sunder 1992, Friedman 1993, Ackert et al. 1997, Ackert and Church 1998). The studies in this literature strand focus on the test of the "prior information equilibrium pricing prediction model" (PI) versus the "fully revealing rational-expectations equilibrium prediction model" (RE). Both prediction models will be explained in more detail in Section 3 below. In summary, this literature strand shows that markets are generally able to aggregate information quite successfully. PI predictions seem to be a good benchmark for trades in early periods, whereas the RE predictions appear more accurate in later periods. Plott and Sunder (1988), for example, argue as follows: "Rational expectations can be seen either as a static theory of markets (e.g., as in the efficient market literature in finance) or as an end-point of a dynamic path of adjustment." (p. 1104)

Our experiment is novel in that it combines both literature strands and introduces statedependence in the SSW framework. In our new framework, insider information is defined as the knowledge of the state. The aim of our study is to analyze how informational aspects, including the existence of inside knowledge, influence price formation and market performance.

In our experiment, the dividend paid by an asset, in each of 15 periods, has four possible values and is the same for all traders. However, in each period, the dividend is stochastic and its distribution function depends upon one of two possible states of the world. In other words, the state determines the probabilities with which the respective dividends are drawn. The "state of the world" is determined at the beginning of the experiment and stays the same over all periods. Traders generally do not know the state but are informed that the probability of each state is 50 percent. This is the prior belief, which determines the ex-ante expected fundamental value of the assets. Based on the observed dividends during the experiment, this belief can be updated according to the method of Bayes, resulting in ex-post expected fundamental values (BFVs) of the assets. In some of

\footnotetext{
5 Unlike the work of Sutter et al. (2012), which uses randomly assigned and free private information, King (1991) investigates costly private information that is auctioned off before the markets start.
} 
the experimental markets informational asymmetry is established via a random assignment of cost-free information about the state to some inside traders.

We investigate how information is processed and disseminated trough market prices. We are particularly interested in two informational aspects: (1) the role of traders who are informed about the true state (insiders), and/or (2) the impact of the provision of Bayesian updates of the assets' state-dependent fundamental value to all traders. We compare the outcomes in markets where two traders with insider information about the actual "state of the world" are present (and the presence is common knowledge) to the outcomes in markets without any insider information. Additionally, in half of the markets with insiders and half of the markets without insiders, we provide all traders in every period with updated BFVs. In all four resulting treatments, to scrutinize traders' ability to anticipate uncertain future outcomes, a key issue in financial markets, we elicit traders' expectations about the future market prices at the beginning of each period and provide monetary incentives for the accuracy of their predictions.

Our main results are the following: We find bubbles to occur rarely in all treatments, even though all traders are inexperienced, i.e., never participated in market experiments before. Markets with asymmetrically informed traders exhibit smaller price deviations from fundamentals, suggesting higher market efficiency. The provision of BFVs has little to no effect. Behavior of in- and outsiders differs in early periods but converges over the course of the markets. On average, we find outsider limit buy/sell prices to be lower (higher) in the "good" ("bad") state and outsiders to hold less (more) assets in "good"state ("bad"-state) markets compared to insiders. Insiders manage to exploit their superior position and are able to earn higher profits. With regard to price expectations, we find forecasts and actual market prices to be highly correlated. Forecast precision, however, seems to be impeded by the presence of insiders, while the provision of BFVs seems to have no impact on forecast quality.

The remainder of this paper is structured as follows: Section 2 presents the experimental market design and describes the experimental procedures. Section 3 introduces two behavioral models and provides testable hypotheses. Section 4 reviews these hypotheses in the face of the results of the experimental markets. Section 5 gives a summary and concludes. 


\section{Laboratory Markets and Experimental Procedures}

We conducted the computerized experiment in the Göttingen Laboratory of Behavioral Economics at the University of Göttingen, Germany, based on the z-tree software package (Fischbacher 2007).

A total of 192 subjects participated in 32 markets with six traders, each. Participants were student volunteers recruited for a decision-making experiment via ORSEE (Greiner 2004). All participants were Bachelor or Master Students in business administration or international economics at the University of Göttingen and thus had some background in economics.

Each subject assumed the role of a trader in an asset market. Six participants (henceforth traders) participated in a market lasting 15 periods. Each experiment session involved two or three independent markets. At no time, traders did know the identity of other traders in the market. A market lasted 15 periods and involved trading in call auctions (for buying and selling) in each period.

The experimental sessions were conducted in two parts. In the first part, risk preferences were elicited using lottery choices following Holt and Laury (2002) (see Appendix A for more details). Trading in the call-auction market took place in the second part. For both parts traders were given detailed written instructions. For the first part, written instructions were individually provided. For the second part, instructions were read aloud in a briefing room and supplemented by a presentation of screenshots which included all screens traders encountered during the experiment. Instructions and screenshots of the program are provided in the Appendix C. The whole process before the call-auction market started lasted on average about 45 minutes. During the entire session traders were not allowed to talk to each other.

\subsection{Characteristics Common to All Sessions}

At the beginning of each experimental market each trader is endowed with 10 assets and 10,000 ECU working capital. We have chosen to provide the same endowment to all traders to prevent trading merely due to the desire to realign portfolios. King et al. (1993) found no significant effect of equal endowments on bubble formation. Each trader's initial endowment in ECU is large enough to buy at least a quarter of the other traders' assets in a market at initial fundamental values. Short selling is not permitted. The initial working capital has to be repaid at the end of the market session. Traders' asset and working capital holdings are carried over from one period to the next.

Prior to the trading stage, at the beginning of each period, traders have to state their expectations about the prospective market prices of the present and all subsequent 
trading periods. Thus, each trader has to state in each period $t \in(1, \ldots, 15)$ a total of $(16-t)$ forecasts. To create an incentive for participants to care about forecast precision, participants are rewarded (in ECU) for the accuracy of each forecast. ${ }^{6}$ If the forecasted price is within a 10 percent, 10-20 percent or 20-30 percent range, a respective reward of $5 \mathrm{ECU}, 2 \mathrm{ECU}$ or $1 \mathrm{ECU}$ is paid. For less accurate forecasts no reward is paid. Over the course of the 15 market periods, for any period $t(1 \leq t \leq 15) t$ predictions are requested and thus a reward may be obtained up to $t$ times. In each period, after all traders have stated their predictions, trading commenced in a callauction market.

Each of the 15 market periods on average lasted five minutes (including forecasts). In each period, assets with an initial lifetime of 15 periods can be traded. Each asset pays the same dividend to all its holders in a market. The dividend is randomly drawn after the trading at the end of each period. It can take a value of 10 ECU, 20 ECU 40 ECU, or 80 ECU. The fundamental value of an asset is determined by the dividend stream that it generates to its holder. It corresponds to the sum of all expected future dividends. Consequently, the fundamental value declines to zero in the course of a market. After the final payment of the dividend in the last period, the asset becomes worthless.

Since our research focus lies in the propensity of markets to aggregate and disseminate information, we incorporate state-dependency of assets, as in Camerer and Weigelt (1991). Like in the SSW type markets, the dividend from holding an asset does not differ across traders. That means that markets have only one "type" of trader with regard to dividend value. However, the expected dividend depends upon the "state of the world", which is randomly drawn at the beginning of a market. There are two equally likely states. State 1 is called the "good" and State 2 the "bad" state. The set of possible dividend values is equal in both states of the world but dividend values occur with different probabilities. We have chosen probability distributions of the dividends in order to focus the subjects' attention on the two different expected values for the "good" and "bad" state and to determine two clearly distinguishable states of the world. Actual dividends originate from independent random draws out of the set $\{10,20,40,80\}$ of possible dividends. The expected dividend per period in a given state is given by the probability weighted sum of the possible dividends. Table 1 provides the possible per period dividend values and the corresponding probabilities of occurrence under each of the two states. It also provides the expected per period dividend $E D_{S}$ in each state $S \in$ $(1,2)$.

\footnotetext{
${ }^{6}$ We use incentivized belief elicitation because it can be expected that participants exert more effort to forecast correctly and that these forecasts are more accurate than non-incentivized, as was, for example, found by Gächter and Renner (2010).
} 
Table 1: Possible Dividend Values and Probabilities

\begin{tabular}{ccc}
\hline $\begin{array}{c}\text { Possible } \\
\text { Dividends }\end{array}$ & $\begin{array}{c}\text { Probability in } \\
\text { "Good" State }(S=1)\end{array}$ & $\begin{array}{c}\text { Probability in } \\
\text { "Bad" State }(S=2)\end{array}$ \\
\hline 10 & 0.1 & 0.4 \\
20 & 0.2 & 0.3 \\
40 & 0.3 & 0.2 \\
80 & 0.4 & 0.1 \\
\hline$E D_{S}$ & 49 & 26 \\
\hline
\end{tabular}

In the "good" state the probabilities of the higher dividends are larger than in the "bad" state, resulting in a higher expected dividend value per period and a higher FV in each period. The expected dividend per period is 49 in the "good" state and 26 in the "bad"' state. In the first period, with no information about the state at hand the expected dividend is 37.5. This value changes after each period's dividend draw according to Bayes' theorem, since the updated probability to be in one state or the other also changes according to this rule. For a given "state of the world", the FV is given by the product of the expected dividend per period and the number of remaining periods the dividend is paid. Formally, the FV in State $S$ and period $t$ is given by $(16-t) E D_{S}$, assuming no discounting.

FVs in both states reduce after each period by the expected dividend per period. Given the ex-ante probabilities for the states and actual dividend draws Bayesian inference is possible due to the different drawing probabilities of the dividends in both states. The Bayesian fundamental value (BFV) in a given period is the probability-weighted mean of the FVs in the "good" and "bad" state in the respective period. The weights are given by the conditional probabilities based on Bayesian inference. The probabilities of dividends in both states of the world, the probabilities for both states, and the fundamental values in both states are provided to all traders in the (read-aloud) experiment instructions and are thus considered as common knowledge.

To have control over the drawn dividends and to render markets comparable, we follow the approach of Sutter et al. (2012). We randomly draw a sequence of 15 realizations of the dividend (one for every period) with the respective probabilities in the "good" state and "mirror" this sequence for the realizations of the dividends in the "bad" state. This is easily feasible due to the symmetric framework. We consciously choose a sequence that does not "fully" reveal the underlying state from the start. The resulting two sequences, one for each state, are used during all markets.

In the experiment we have chosen the states in such a way that one half of the markets were in the "good" state and the other half in the "bad" state. Table 2 provides, for each state, the sequence of the asset's actual dividend draws (Ds), the actual FVs (AFVs) and the (depending on the dividend draws) updated Bayesian FVs (BFVs). The last column of this table provides the conditional probabilities of the actually prevailing state. 
Table 2: Sequence of Dividend Draws and Corresponding Fundamentals in the "Good" and "Bad" State

\begin{tabular}{c|cccc|cccc|c}
\hline \multirow{2}{*}{ Period } & \multicolumn{4}{|c|}{ "Good" State } & \multicolumn{4}{|c}{ "Bad" State } & Cond. Prob. \\
& FV & D & AFV & BFV & FV & D & AFV & BFV & for the State \\
\hline 1 & 735 & 40 & 720 & 563 & 390 & 20 & 420 & 563 & 0.50 \\
2 & 686 & 80 & 680 & 557 & 364 & 10 & 400 & 493 & 0.60 \\
3 & 637 & 20 & 600 & 594 & 338 & 40 & 390 & 381 & 0.86 \\
4 & 588 & 10 & 580 & 533 & 312 & 80 & 350 & 367 & 0.80 \\
5 & 539 & 80 & 570 & 413 & 286 & 10 & 270 & 413 & 0.50 \\
6 & 490 & 80 & 490 & 444 & 260 & 10 & 260 & 306 & 0.80 \\
7 & 441 & 20 & 410 & 429 & 234 & 40 & 250 & 246 & 0.94 \\
8 & 392 & 40 & 390 & 376 & 208 & 20 & 210 & 224 & 0.91 \\
9 & 343 & 80 & 350 & 334 & 182 & 10 & 190 & 191 & 0.94 \\
10 & 294 & 10 & 270 & 292 & 158 & 80 & 180 & 158 & 0.98 \\
11 & 245 & 40 & 260 & 238 & 130 & 20 & 100 & 137 & 0.94 \\
12 & 196 & 20 & 220 & 192 & 104 & 40 & 80 & 108 & 0.96 \\
13 & 147 & 80 & 200 & 143 & 78 & 10 & 40 & 82 & 0.94 \\
14 & 98 & 40 & 120 & 97 & 52 & 20 & 30 & 53 & 0.98 \\
15 & 49 & 80 & 80 & 49 & 26 & 10 & 10 & 26 & 0.99 \\
\hline
\end{tabular}

Notes: $\mathrm{FV}=$ Fundamental Values, $\mathrm{D}=$ Dividends, $\mathrm{AFV}=$ Actual Fundamental Values, $\mathrm{BFV}=$ Bayesian Fundamental Values.

As can be seen in Table 2, the dividends at the beginning correctly suggest the underlying state, then by period 5 reset state probabilities to 50:50, and subsequently again correctly suggest the underlying state. Toward the end, dividends reveal the state with almost certainty. This characteristic of the dividend stream has the desirable property to introduce initial uncertainty regarding the real state as it is surely frequently present on real markets.

Trading in the call market in each period lasts a maximum of 240 seconds. During the first 120 seconds traders have the opportunity to submit a purchase offer; in the second 120 seconds they have the opportunity to submit a sale offer. Each trader may determine one buy and one sell limit order per period to buy/sell a certain number of assets. A buy (sell) order consists of the maximum (minimum) price which a trader wants to pay (is willing to accept) per asset and the maximum number of assets the trader is willing to buy (sell) at that price. Traders are not obliged to submit buy and/or sell orders. In the case of a "zero order" no assets are bought and/or sold at any market price; traders just keep their stock of assets. At no point of time, traders get to know the offers of others.

All bids and asks within a period are submitted simultaneously and are aggregated into market demand and supply. The call market features a market-clearing condition such that demand equals supply in each trading period. Markets are cleared at unitary prices for all transactions within each period so that the trading volumes are maximized. ${ }^{7}$

\footnotetext{
7 The call market institution has the advantage that it yields for each trader a unique trading price per period for all buy and sell orders. Furthermore, Liu (1992) found that call markets are more efficient than
} 
Transactions only take place as long as there are dealers who want to sell at a lower or the same price than other dealers are willing to pay. The market price is determined by the average of the lowest limit buy price and the highest limit sale price for which a transaction takes place. No trader has to pay more for an asset than he/she offered and no trader has to sell for less than he/she asked. If the aggregated market price lies above the chosen sale price the trader is a seller and if the market price lies below the chosen buy price the trader is a buyer. If, depending on the submitted buy and sell orders, no transactions can take place, there is no market price. In this case we referred to the market price as zero.

Ties on the demand and/or selling side are handled using an order precedence rule consisting of the price, quantity and entering time. On the buy (sell) side higher (lower) buy (sell) prices, higher quantities, and an earlier submission time are favored. ${ }^{8}$ Traders are instructed that they might not get all or part of their buy/sell order fulfilled even if they hand in an adequate price.

During the choice of buy and sell offers, traders have to make sure that these are permissible. Firstly, they can never sell more assets than they have at the beginning of the period in their own portfolio. Secondly, never buy more assets as permitted by the available sum of asset holdings of the other traders in their group. Thirdly, never buy more assets at a certain price than permitted by the available trading capital. Fourthly, the limit sell order price must exceed the limit buy order price by at least one ECU.

At the end of the trading state in each period all possible individual transactions are completed, the drawn dividend is announced, and the updated account of asset and trading capital holdings along with the dividend earnings for the current period are presented to the traders. Additionally the results for the accuracy of price forecasts along with the associated earnings are given for the current period. Furthermore, traders are provided with a complete history of relevant information concerning their portfolio (asset and cash holdings etc.) during both phases of the trading stage in each period.

The payout relevant profit (in ECU) to a subject is determined by the available trading capital at the end of the $15^{\text {th }}$ period minus the initial trading capital. It can be alternatively calculated as the sum of the period profits:

Period profit $=$ Number of assets at end of the period $\times$ dividend per asset

+ Proceeds from sold assets

- Expenses for purchased assets

+ Remuneration of market-price forecast(s)

continuous double auction markets in settings were uninformed traders are present jointly with diversely informed insiders (Sunder 1995).

${ }^{8}$ Index $=100 \cdot \mathrm{R}_{\mathrm{p}_{\mathrm{D}, \mathrm{S}}}+10 \mathrm{R}_{\mathrm{q}, \mathrm{S}}+\mathrm{E}$, where $\mathrm{R}_{\mathrm{p}_{\mathrm{D}, S}}$ is the price rank, decreasing with ascending (descending) buy (sell) price; $\mathrm{R}_{\mathrm{q}, \mathrm{S}}$ is the quantity rank, decreasing in the buy (sell) quantity; and $\mathrm{E}$ is the entering order number. Lower rank numbers are favored and a lower index corresponds to a preferred offer. 
Following the method of induced value theory, we expect traders to exhibit a positive utility for money, i.e., to maximize their earnings. Demand for (Supply of) asset is hence induced by a preference for (higher) earnings (Smith 1976).

All trading in the experiment was in terms of Experimental Currency Units (ECU). Earnings were converted into Euros at the end of the market, at a known rate of $0.003 € / E C U)$. Additionally, each trader was paid a show-up fee of $3 €$. A session lasted on average about 2.5 hours. Traders' earnings averaged about $25 €$.

\subsection{Treatments}

We conducted our experiment by using a $2 \times 2$ design. Firstly, the information structure of markets differed across sessions, i.e., the structure of informed and uninformed traders with respect to the true state of nature differed across markets. In the so called $\operatorname{Nin}(B)^{9}$ sessions no participant was given a clue about the true state of nature and it was announced that no trader received information about the state. In the so called Tin(B) sessions two participants in a market are provided on the computer screen with information about the underlying "state of the world" at the beginning of the market. In these sessions it was publicly announced (common knowledge) that there will be two randomly chosen informed traders in each market and that their identity will remain secret to all other participants. The information given to the informed participants was identical and perfect in the sense that it would reveal the state of nature with certainty (this was also common knowledge). By virtue of the design of the markets, insiders and outsiders were the same traders throughout the entire markets. Secondly, we distinguish between sessions where participants were or were not provided with updated conditional probabilities for both states and the corresponding BFVs. The (B) after Nin and Tin indicates that in these markets all traders were provided with updated BFVs in each period.

Table 3 displays a summary of the design parameters of each of our 32 asset markets. Specifically, it gives an overview over the underlying state, the provision of BFVs, and the presence of insiders in each market.

\footnotetext{
${ }^{9}$ When markets with or without insider information are considered together, regardless of the provision of BFVs, we refer to them simply as Tin(B) and Nin(B) markets.
} 
Table 3: Markets and Information Levels

\begin{tabular}{|c|c|c|c|c|c|c|}
\hline $\begin{array}{c}\text { Treatment } \\
\text { No. }\end{array}$ & Label & State & $\begin{array}{l}\text { State } \\
\text { Label }\end{array}$ & BFVs & $\begin{array}{c}\text { Insiders } \\
(\#)\end{array}$ & $\begin{array}{c}\text { Market } \\
\text { No. }\end{array}$ \\
\hline 1 & Nin & $\begin{array}{l}\text { Good } \\
\text { Bad }\end{array}$ & $\begin{array}{l}\text { Nin+ } \\
\text { Nin- }\end{array}$ & No & No & $\begin{array}{l}17,19,21,23 \\
18,20,22,24\end{array}$ \\
\hline 2 & $\mathrm{NinB}$ & $\begin{array}{c}\text { Good } \\
\text { Bad }\end{array}$ & $\begin{array}{l}\mathrm{NinB}+ \\
\text { NinB- }\end{array}$ & Yes & No & $\begin{array}{l}1,3,5,7 \\
2,4,6,8\end{array}$ \\
\hline 3 & Tin & $\begin{array}{l}\text { Good } \\
\text { Bad }\end{array}$ & $\begin{array}{l}\text { Tin+ } \\
\text { Tin- }\end{array}$ & No & Two & $\begin{array}{l}25,27,29,31 \\
26,28,30,32\end{array}$ \\
\hline 4 & TinB & $\begin{array}{c}\text { Good } \\
\text { Bad }\end{array}$ & $\begin{array}{l}\text { TinB+ } \\
\text { TinB- }\end{array}$ & Yes & Two & $\begin{array}{c}9,11,13,15 \\
10,12,14,16\end{array}$ \\
\hline
\end{tabular}

Note: Markets are numbered in the order how the observations were collected during the experimental sessions. 


\section{Informational Models and Hypotheses}

\subsection{Informational Models}

Following the studies of, for example, Plott and Sunder $(1982,1988)$ or Camerer and Weigelt (1991), we test two different models: the prior information equilibrium (PI) model and the fully revealing rational-expectations equilibrium (RE) model. Both models assume traders to be risk-neutral and give different forecasts about trading behavior of differently informed traders. These models can be formalized quantitatively and tested against each other. ${ }^{10}$

The PI-model states that traders do not learn from price signals and only use their prior information to determine the state. They ignore the informational content of market prices (as the aggregated information of others) and speculation possibilities depending on the actions of other traders (Palan 2009). Traders only use Bayes' rule to update their expectations about the true state.

The RE-model additionally states that in equilibrium all traders behave as if they are aware of the entire information of all traders in the market. Thus even uninformed traders have the ability to supplement their prior ("private") information with private information of others via price signals from the market that entail (perfect) information of insiders. ${ }^{11}$ They are aware of the relationship between the market price, the underlying state, and their gains from trade and utilize the market price and their "private" information in their demand decision (Tirole 1982).

In our experiment we chose dividends, prior probabilities of dividends, and states in a manner that fundamentals and hence predictions of the PI- and RE-models clearly differ in both states. Table 4 shows the expected FVs per asset with respect to information, state, and informational model. When there is no inside information in the market, the PI- and the RE-model both predict no trade in both states. According to both theories, all traders have the same expectations about the respective FVs, which equal the updated BFVs. There are no evident gains from and thus no incentives to trade.

When insider information is present, both theories predict that trade will take place since in- and outsiders have different expectations about fundamentals. For the REmodel this is true only for the first period. Assuming in- and outsiders are strict payoff maximizers and place bid prices marginally below and ask prices marginally above their expected FVs, the market price will approximately average the expected FVs.

\footnotetext{
10 We refrain from testing intermediate dynamic models like that of Jordan (1982). These models aren't easy to handle and don't give precise predictions of expected values and therefore prices. Though some works showed that trading in experimental asset markets does seem to follow a kind of "Jordan path" (Plott and Sunder 1982).

11 The RE-model has a close connection to the efficient markets hypothesis. Bid/ask prices reflect diverse private information and thus induce trading actions identical to those if all traders had all market information (Harrison and Kreps 1978).
} 
Table 4: Expected FVs under PI and RE by Information and State

\begin{tabular}{|c|c|c|c|c|c|c|}
\hline \multirow[b]{3}{*}{ Period } & \multicolumn{2}{|c|}{ No Information } & \multicolumn{4}{|c|}{ Inside Information } \\
\hline & \multirow{2}{*}{$\begin{array}{l}\text { "Good" } \\
\text { PI = RE }\end{array}$} & \multirow{2}{*}{$\begin{array}{c}\text { "Bad" } \\
\text { PI = RE }\end{array}$} & \multicolumn{2}{|c|}{ "Good" } & \multicolumn{2}{|c|}{ "Bad" } \\
\hline & & & PI & RE & PI & RE \\
\hline \multirow{2}{*}{1} & \multirow{2}{*}{563} & \multirow{2}{*}{563} & 735 & 735 & 390 & 390 \\
\hline & & & [563] & [563] & {$[563]$} & [563] \\
\hline \multirow{2}{*}{2} & \multirow{2}{*}{557} & \multirow{2}{*}{493} & 686 & 686 & 364 & 364 \\
\hline & & & [557] & [686] & [493] & [364] \\
\hline \multirow{2}{*}{3} & \multirow{2}{*}{594} & \multirow{2}{*}{381} & 637 & 637 & 338 & 338 \\
\hline & & & [594] & [637] & [381] & [388] \\
\hline \multirow{2}{*}{4} & \multirow{2}{*}{533} & \multirow{2}{*}{367} & 588 & 588 & 312 & 312 \\
\hline & & & {$[533]$} & [588] & [367] & [312] \\
\hline \multirow{2}{*}{5} & \multirow{2}{*}{413} & \multirow{2}{*}{413} & 539 & 539 & 286 & 286 \\
\hline & & & [413] & [539] & {$[413]$} & [286] \\
\hline \multirow{2}{*}{6} & \multirow{2}{*}{444} & \multirow{2}{*}{306} & 490 & 490 & 260 & 260 \\
\hline & & & [444] & [490] & [306] & {$[260]$} \\
\hline \multirow{2}{*}{7} & \multirow{2}{*}{429} & \multirow{2}{*}{246} & 441 & 441 & 234 & 234 \\
\hline & & & [429] & [441] & [246] & [234] \\
\hline \multirow{2}{*}{8} & & & 392 & 392 & 208 & 208 \\
\hline & $3 / 6$ & 224 & [376] & [392] & [224] & [208] \\
\hline 9 & 324 & 101 & 343 & 343 & 182 & 182 \\
\hline 9 & 334 & 191 & [334] & [343] & [191] & [182] \\
\hline & & & 294 & 294 & 156 & 156 \\
\hline 10 & 292 & 158 & [292] & [294] & [158] & [156] \\
\hline & & & 245 & 245 & 130 & 130 \\
\hline 11 & 238 & 137 & [238] & [245] & [137] & [130] \\
\hline 12 & 192 & 108 & 196 & 196 & 104 & 104 \\
\hline 12 & 192 & 100 & [192] & [196] & [108] & [104] \\
\hline & & & 147 & 147 & 78 & 78 \\
\hline 13 & 143 & 82 & [143] & [147] & [82] & [48] \\
\hline 14 & 97 & 53 & 98 & 98 & 52 & 52 \\
\hline $1 \mathrm{~T}$ & נו & & [97] & [98] & [53] & [52] \\
\hline 15 & 49 & 26 & 49 & 49 & 26 & 26 \\
\hline 15 & & & [49] & [49] & {$[26]$} & {$[26]$} \\
\hline
\end{tabular}

Notes: Figures show for the case of insider information the known FVs for informed and expected FVs for [uninformed] traders. The bold figures identify the convergence period as defined in Section 4.1.

Since in the first period the resulting market price is higher (lower) than the BFV of 563 in the "good" ("bad") state, outsiders supplement their prior information with this price signal and are able to infer the correct state under the RE-model assumptions. Informed traders can thus only take advantage of their superior position in the first period. On the other hand, under the PI-model trade may virtually take place throughout all periods, assuming availability of assets on the supply side. Since market participants ignore the informational content of market prices, expectations about fundamentals only converge slowly to the true value, which leads to a more persistent superior position of insiders. According to both models, bid and ask behavior will result in asset allocations where 
insiders hold more (less) assets in the "good" ("bad") state than outsiders. This is especially true under the PI-model.

\subsection{Hypotheses}

To facilitate the illustration of the results in the following section our analysis focuses around six hypotheses.

Hypothesis 1: Trading prices converge toward the actual FV under all treatment conditions, but the convergence is faster in markets with insider information and markets where traders are provided with BFVs.

In our markets, convergence toward fundamentals depends substantially on the accuracy of the probability assessment. This is a complex task, especially in an experimental situation, where time is limited. Markets aggregate information. However, it will take time for prices to track the FV. ${ }^{12}$ Following Romer (1993), the dissemination of privately held information and/or expectations is likely to cause lagged price movements. Proponents of the "efficiency camp" of insider trading argue that convergence of market prices toward fundamentals is faster when inside information is present (Manne 1984, Engelen and Liedekerke 2007, McGee 2008). Sutter et al. (2012) and Dufwenberg et al. (2005) provide experimental evidence that markets where some traders have an informational/experiential edge above others show a significantly better performance in terms of market efficiency. Since people are unlikely to carry out Bayesian inference by themselves (Kahneman and Tversky 1972, Camerer 1999, Rabin and Schrag 1999), we expect markets where traders are provided with BFVs to converge faster toward fundamentals than markets that are not.

Hypothesis 2: Bubbles occur, but the introduction of asymmetrically informed traders, or the provision with BFVs significantly reduces the occurrence and extent of bubbles.

A vast literature shows that the bubble-and-crash phenomenon is strikingly robust in SSW markets (see footnote 3). Since the introduction of insider information is expected to enhance market performance in terms of the duration of equilibrium adjustment of market prices, we expect markets with asymmetrically informed traders to be less prone to bubble formation than markets with symmetrically informed traders, a result also observed by Sutter et al. (2012) and Dufwenberg et al. (2005). Similarly, given that markets that are provided with BFVs are expected to converge faster toward fundamentals than markets that are not, we also expect them to exhibit smaller bubbles.

\footnotetext{
${ }^{12}$ Forsythe et al. (1984) argue that "investors bring only their private information to the market and only after traders have observed prices will they learn the information necessary to achieve the [fully revealing rational-expectations equilibrium]." (p. 973)
} 
Hypothesis 3: In early periods, trading behavior of uninformed traders differs from that of informed traders but converges along with the market price toward that of informed traders. Uninformed traders learn to grasp the correct state and to trade accordingly.

Informed traders condition their trading behavior on private information and uninformed traders adapt their trading behavior based on the belief that informed traders only trade if it is advantageous for them to do so (King 1991), thereby revealing gradually the underlying state. In a fully revealing RE all private information held by informed traders is (sooner or later) revealed via the market price (King 1991). To the same extent as information is revealed, we expect that an adaptation of the trading behavior of in- and outsiders takes place.

Hypothesis 4: In the "good" state, we expect insiders to hold more assets than outsiders, and in the "bad" state, outsiders to hold more assets than insiders.

Given the different information structures of in- and outsiders, we expect the two types to show a significantly different buying and selling behavior. In Table 4 above we calculate the FV expectations of in- and outsiders. Based on these calculations we derive that insiders buy/hold more assets in the "good" state and outsiders in the "bad" state, under both the PI- and RE-assumption. The predicted asymmetric asset distribution should at least hold true in earlier periods, since we expect outsiders to learn in the course of the market.

Hypothesis 5: Informed traders have a trading advantage and earn superior profits.

Given that, especially in the beginning of the markets, insiders are able to buy and sell their assets for advantageous prices they should benefit from their superior informational position.

Hypothesis 6: Elicited price expectations and actual market prices are highly correlated. Thereby, we expect predictive power to be greater in markets with inside information, and in markets where traders are provided with BFVs.

There is a certain circularity in the market-price development process since current prices depend on expectations about future prices; but both are simultaneously influenced by current price levels and trends (Ball and Charles A. Holt 1998). Selffulfilling price expectations can render observed market prices independent of the asset's fundamentals, leading to bubbles, in which even rational traders get involved in the expectation of even "greater fools".13 Expectations should therefore provide crucial information about the market price development.

\footnotetext{
${ }^{13}$ Such bubbles are referred to as "rational growing bubbles" (Camerer 1989) or simply "rational bubbles" (Diba and Grossman 1988a, 1988b). They "reflect a self-confirming belief that the stock price depends on a variable (or a combination of variables) that is intrinsically irrelevant" (Diba and Grossman 1988a, p. 520). Porter and Smith (1995) however find that "subjects report a tendency to think that if the market turns [when the bubble bursts] they will be able to sell ahead of the others, but then are "amazed" at the speed with which the crash occurs." (p. 513)
} 


\section{Experimental Results}

\subsection{Equilibrium Adjustment of Prices}

Figure 1 illustrates the main findings of our experiment by showing the course of the average equilibrium market prices in our four treatments. Each curve in the four graphs represents four markets under equal conditions with respect to state, insider information, and the provision of BFVs. All four graphs show the tendency of convergence toward the correct state. Most intriguing, the ubiquitous tendency of earlier laboratory asset markets with well-defined declining fundamental value and inexperienced traders to exhibit a well-known bubble-and-crash pattern is not observed in this aggregated examination, independent of the provided information structure.

Strikingly, trade in both states starts, regardless of the presence of insiders and/or the provision of BFVs, on aggregate closer to fundamentals in the "bad" state, indicating risk aversion for the average trader. ${ }^{14}$ Indeed, we find slight risk aversion for the average trader in our risk pretests and in the personal assessment of one's own attitude toward risk in the ex-post questionnaire (see Appendix A, Table A. 1 to Table A. 4). Given that average risk attitudes are very similar in all markets, we cannot find a significantly negative Spearman correlation between the average risk-aversion measure in a market and the $1^{\text {st }}$ period market price. ${ }^{15}$ However, when counting the number of risk-averse (not risk-neutral, or risk-loving) traders per market, we find a slightly significant Spearman correlation for Risk-Test 1 following Holt and Laury (2002) ( $\rho=-.3049$, pvalue $=.0897, N=32$ ). Despite the substantial initial deviations from fundamentals (especially in the "good" state), we observe a clear tendency of convergence of aggregate market prices toward fundamentals of the actually underlying state around the fifth period. Intuitively, convergence starts in either state somewhere between the two fundamentals. This implies that we should observe convergence from below in the "good" state and convergence from above in the "bad" state. In the following we explore Hypothesis 1.

While markets on aggregate show a clear convergence pattern, individual markets show substantial diversity. Some markets perform much better than others in terms of convergence toward the FV of the underlying state. Ten out of 32 observed markets even never converge to it. ${ }^{16}$ We consider market prices as "converged" if they approach the respective $\mathrm{FV}$ as close as $\pm 20 \%$ and stay in this range until the end of the market or no more trading takes place. For the very last periods, our definition of convergence

14 Since dividend draws can be considered as lotteries, trading prices below (above) fundamentals indicate risk aversion (loving) of the average market participant. Hence, the ratio of the realized price and the fundamental value can serve as a proxy for average risk attitude in a market (Chen et al. 2004).

15 The algebraic signs point in the intuitive direction that higher risk aversion in a market leads to a lower starting price. Only for "Risk-Test $2 \mathrm{~b}$ " the sign is counterintuitive.

${ }_{16}$ Markets 4, 6, 9, 10, 15, 21, 26, 28, 30, 32 never converged toward the FV of the actual underlying state using the applied convergence measure. 
requires at least two consecutive periods without trading, when market prices previously have deviated out of the range. ${ }^{17}$ Figure 2 shows the course of individual market prices for all markets in the four treatments. As seen, market prices initially fluctuate more erratically, but converge in most cases, sooner or later, toward the genuine state. Table 5 presents the average convergence period by treatment and the individual market convergence periods for the markets that have converged.

To test for general convergence, we count for each treatment the number of markets that have converged. Applying one-sided binomial tests to the number of converged versus the number of non-converged markets, we find a significant tendency of convergence only for Nin, where seven out of eight markets converge ( $p$-value $=.0039$ ). The hypothesis of general convergence is neither confirmed for NinB nor for Tin or TinB markets, when analyzed separately.

When pooling the Nin and NinB markets, we observe 13 of 16 markets to converge, which yields statistical significance for general convergence $(\mathrm{p}$-value $=.0106$, one-sided binomial test). Pooling Tin and TinB markets, we observe only 9 out of 16 markets to converge, implying no statistical significance. This indicates that the presence of insiders does not enhance but rather defer market convergence. On the other hand, confidence intervals for the absolute deviations from fundamentals are for the majority of periods narrower for Tin(B) than for Nin(B) markets. Although not statistically significant, this suggests that the above result lack of convergence in Tin(B) markets is driven by the small number of independent markets.

Result 1: Using our simple counting measure, we only observe a general convergence toward fundamentals in Nin(B) markets. Our test for general convergence indicates that the presence of insiders defers convergence. This result, however, might be an artifact produced by the relatively small sample size. The provision of BFVs has no effect on convergence.

\footnotetext{
17 This "rule" has been relaxed/adjusted in some markets, where the measure in the last five periods trespassed the range in only one period, but was adhered to before, so that the assumption of convergence seems prudent. This "correction" has the aim to obtain a more "organic" and adequate measure of convergence. When no trading occurs, no pair of traders is willing to trade away from fundamentals, indicating that all traders are aware of the actual FV and that it is common knowledge (as defined by Aumann 1976). There is no opportunity to "fool" another trader.
} 
Figure 1: Average Market Prices
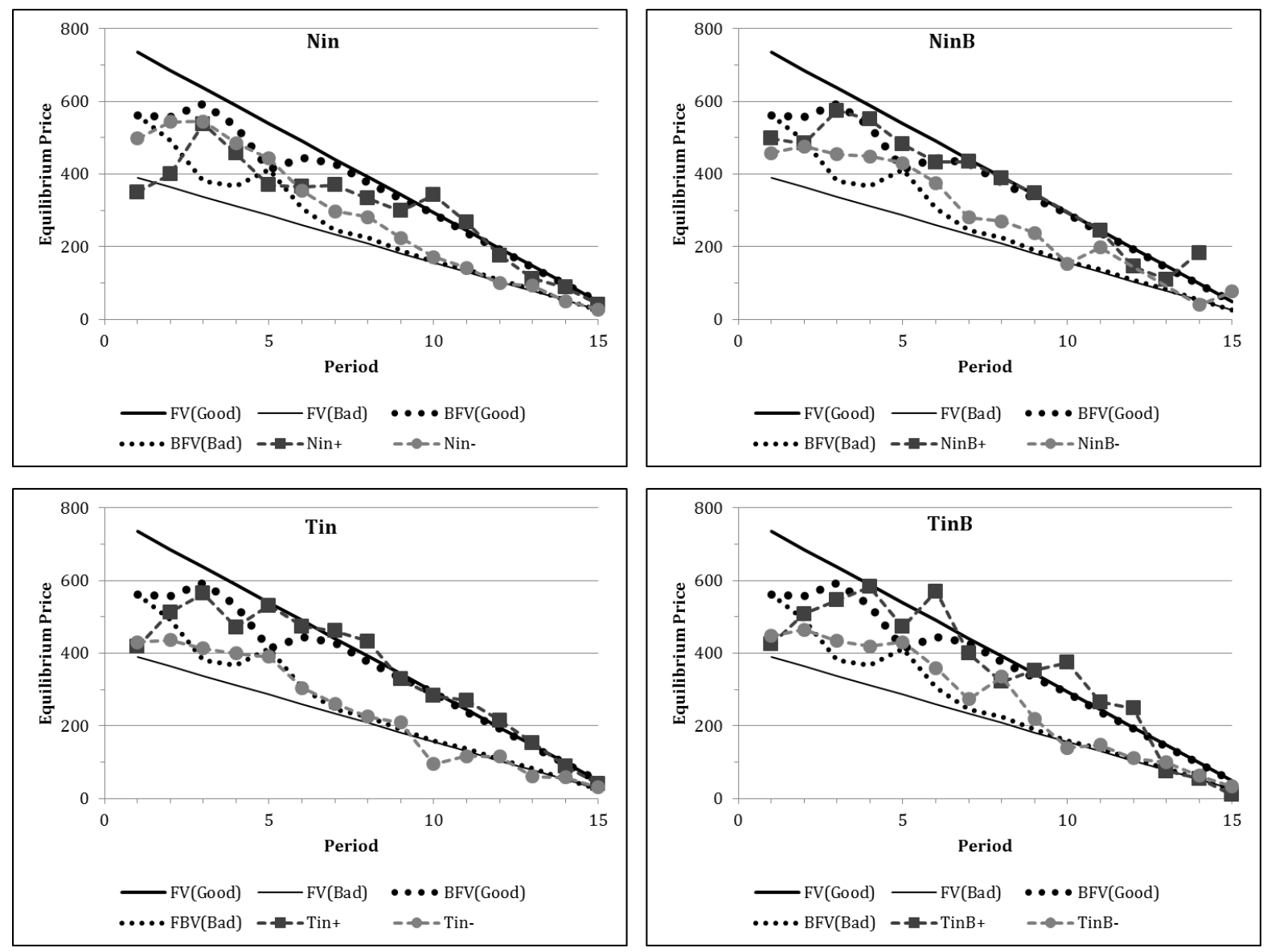

The trajectory of average market prices exhibits clear differences in comparison to most of earlier experiments using the SSW framework. Even in Nin markets the price course resembles that of markets with experienced traders or markets with a composition of traders with mixed information or experience levels (see, for example, Dufwenberg et al. 2005, Haruvy et al. 2007, Hussam et al. 2008, Sutter et al. 2012). Additionally, convergence, as we have defined it, occurs on average later than predicted by the PI- and RE-models, ${ }^{18}$ except for NinB+ and Tin-. We thus conclude that neither the PI- nor the RE-model provide indeed good approximations of asset markets in our symmetric and asymmetric information settings. This finding stands in contrast to the previously mentioned literature on markets involving one-period assets and asymmetric information.

\footnotetext{
${ }^{18}$ Both, the PI- and RE-models, predict convergence to occur (as we define it) in the sixth period in both states, when no insiders are present. The PI-model predicts convergence in the first and in the sixth period and the RE-model predicts convergence in the first and in the second period, in the "good" and "bad" state, respectively, when insiders are present.
} 
Figure 2: Individual Market Prices
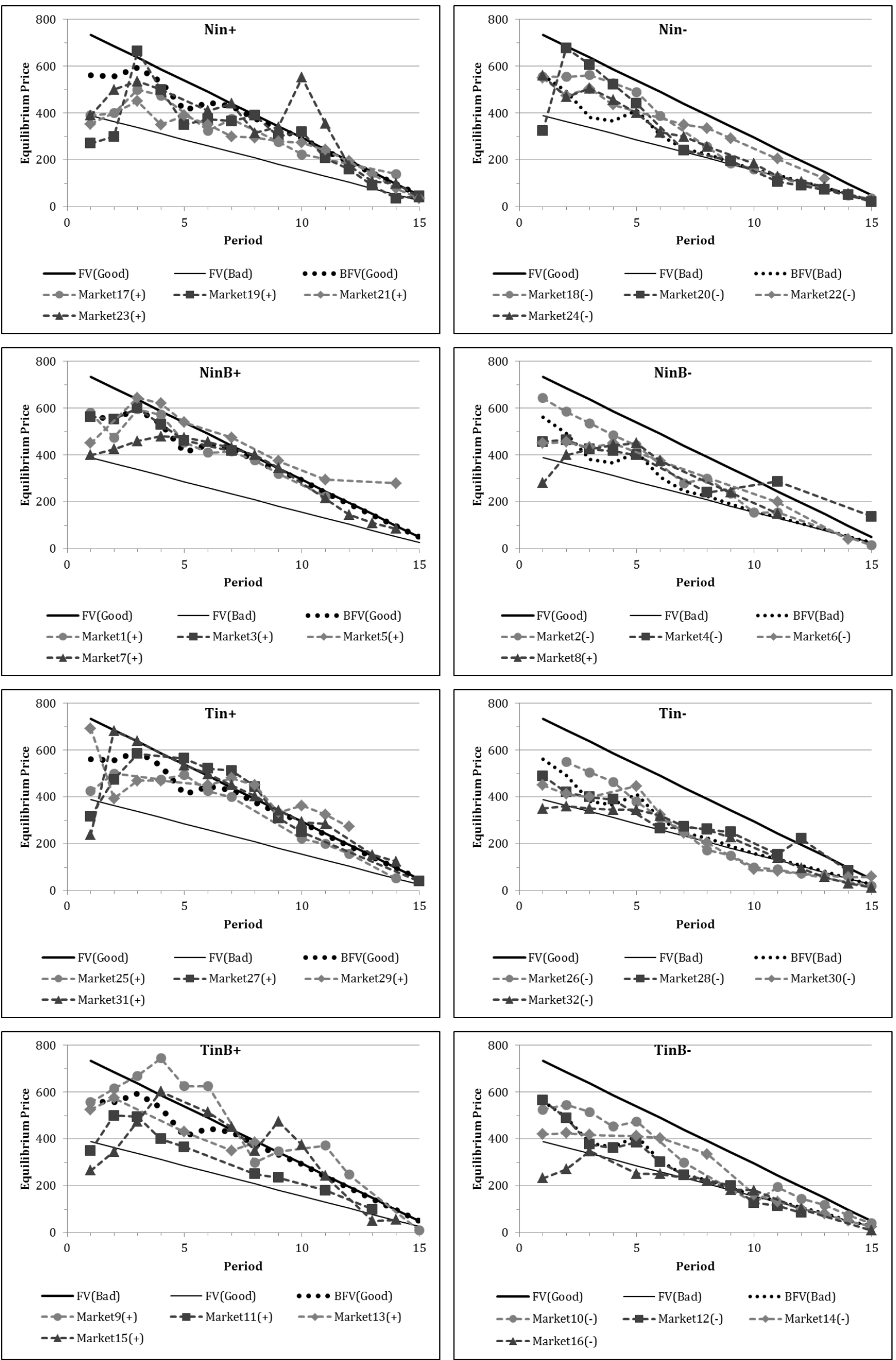
Table 5: Average Convergence Period

\begin{tabular}{cccc}
\hline $\begin{array}{c}\text { State } \\
\text { Label }\end{array}$ & $\begin{array}{c}\text { Average Period of } \\
\text { Convergence }\end{array}$ & $\begin{array}{c}\text { Individual Markets } \\
\text { Convergence Periods }\end{array}$ & $\begin{array}{c}\text { Market } \\
\text { No. }\end{array}$ \\
\hline NinB+ & 5.3 & $3,2,2,14$ & $1,3,5,7$ \\
NinB- & 10.0 & $10,--,--, 10$ & $2,4,6,8$ \\
TinB+ & 11.0 & $--, 14,8,--$ & $9,11,13,15$ \\
TinB- & 6.0 & $--, 6,9,3$ & $10,12,14,16$ \\
Nin+ & 13.3 & $11,15,--, 14$ & $17,19,21,23$ \\
Nin- & 9.5 & $9,6,14,9$ & $18,20,22,24$ \\
Tin+ & 7.3 & $11,3,13,2$ & $25,27,29,31$ \\
Tin- & -- &,,,-------- & $26,28,30,32$ \\
\hline
\end{tabular}

Notes: Markets that did not converge are denoted by "--“. Averages are computed using converged markets only.

\subsection{Over- and Undervaluation of Market Prices}

This chapter focuses on Hypothesis 2. As mentioned earlier, bubbles didn't occur in aggregated form. However, some markets exhibited patterns that, though smaller than in many previous experiments, can be considered as price bubbles. In the following, we define a price bubble as a deviation of market prices from fundamentals by more than $30 \%$ in at least two consecutive periods. Since markets firstly must somehow fathom the actually underlying state, we consider, however, only deviations after the fifth period, in the "bad" state. Otherwise, in the "bad" state, market prices in the first periods would often misleadingly signal bubbles, when in fact just the "natural" adaption process takes place. Given our definition of market convergence, a bubble can evidently only occur before a market converges.

Using our definition of bubbles, we find four markets $(10,22,23$, and 29) to exhibit a bubble pattern. Market 9, the market with the, at the first glimpse, ostensibly most obvious deviation pattern, exceeds fundamentals in the $4^{\text {th }}$ period by "only" $27 \%$, and is thus not considered to exhibit a bubble pattern. Table 6 gives an overview of markets that exhibit bubble patterns, the duration of the bubble and the convergence period. The occurrence of bubbles seems to have no relation to the presence of insiders, the provision of BFVs, or the underlying state.

To additionally gauge the severity of market-price deviations from fundamentals, i.e., differences in market performance, also when markets don't exhibit bubble patterns, we employ two deviation measures, ${ }^{19}$ both developed by Stöckl et al. (2010).

${ }^{19}$ Given the high correlation of these deviation measures with other calculated "bubble" measures we restrain our analysis with the focus on these potentially most reliable measures, RD and RAD. These measures are robust to variations in the number of market periods, the determination of the FV and dividend distribution/variation. 
Table 6: Markets Exhibiting Bubble Patterns

\begin{tabular}{cccc}
\hline Market & $\begin{array}{c}\text { State } \\
\text { Label }\end{array}$ & $\begin{array}{c}\text { Bubble } \\
\text { in Periods }\end{array}$ & $\begin{array}{c}\text { Converged } \\
\text { in Period }\end{array}$ \\
\hline 10 & TinB- & $11-15$ & -- \\
22 & Nin- & $7-13$ & 14 \\
23 & Nin+ & $10-11$ & 12 \\
29 & Tin+ & $11-12$ & 13 \\
\hline
\end{tabular}

The applied average bias measure for a market calculates the relative deviation (RD) as the average difference between the market price $\left(P_{t}\right)$ and the fundamental value $\left(F V_{t}\right)$ normalized by the average fundamental value $(\overline{F V})$. It measures the average relative distance between the market price and the fundamental value. A value of \pm 0.1 indicates that the assets are on average overvalued (undervalued) by $10 \%$ relative to the average fundamental value.

$$
R D=\frac{1}{15} \sum_{t=1}^{15}\left(\frac{P_{t}-F V_{t}}{\overline{F V}}\right)
$$

The applied average dispersion measure for a market calculates the relative absolute deviation (RAD) as the average absolute difference between the market price $\left(P_{t}\right)$ and the fundamental value $\left(F V_{t}\right)$ normalized by the average fundamental value $(\overline{F V})$. It measures the average absolute distance between the period market price and the fundamental value. A value of 0.1 indicates that the assets price differs on average by $10 \%$ from the average fundamental value.

$$
R A D=\frac{1}{15} \sum_{t=1}^{15}\left(\frac{\left|P_{t}-F V_{t}\right|}{\overline{F V}}\right)
$$

Both measures are used to get a first impression of differences in price deviations from fundamentals between treatments. We conduct two-sided Mann-Whitney U tests with the null hypothesis of no difference for both deviation measures. Table 7 displays the results. RDs are not significantly different when compared by treatment, due to the fact that negative deviations in the "good" and positive deviations in the "bad" state cancel each other out. The comparison of RADs shows that the provision of BFVs is only conducive to market performance when no insiders are present. The presence of insiders enhances performance compared to the situation without insiders, however, only when no BFVs are given. The performance of markets where insiders are present and BFVs are given together is indistinguishable to markets where only one of these features is at work.

To check the robustness of the results above and for a deeper understanding of potential factors that influence price formation and thus over- or undervaluation of equilibrium markets prices, we conduct panel-regressions with markets as cross sections $(m=$ 
$1, \ldots, 32)$. The dependent variable is derived from the above mentioned RD measure (Stöckl et al. 2010), denoted in percent. It is defined as:

$$
R D_{m t}=\frac{P_{m t}-F V_{t}}{\overline{F V}}
$$

where $R D_{m t}$ measures the difference between the market price of period $t\left(P_{t}\right)$ and the respective fundamental value $\left(F V_{t}\right)$, normalized by the average fundamental value $(\overline{F V})$ (Stöckl et al. 2010). The index $m$ denotes the market.

We control for treatment effects by using dummy variables for different treatment features (considering Nin+ as the control group) and their interactions. In particular, we control for the "state of the world" (State, which is equal to one in the "bad" state and zero otherwise), for the provision of BFVs (Bayes, which is one when BFVs are given and zero otherwise), and for the presence of insiders (Insiders, which is equal to one, when insiders are present, and zero otherwise). Additionally, we control for autocorrelation by inclusion of the dependent variable with a lag of one period (L. $R D$ ), for a time trend within markets by inclusion of a period variable (Period), and for the trading volume (Volume). Furthermore we included the drawn dividend in the prior period (L.Dividend) and the number of risk-averse traders within a market (\# Risk Averse) as explanatory variables. The results are shown in Table 8.

Since both regression models shown in Table 8 display qualitatively the same results, we focus our analysis on Model 2. The model shows that price deviations are strongly pathdependent; a price deviation in the previous round ( $L . R D$ ) has a significantly positive effect on the current price deviation. Price deviations decrease over time as participants gain trading experience. Period has a significantly negative effect on price deviation. The last dividend (L. Dividend) has a significantly positive (euphoriant price boosting) effect, the higher the dividend in the previous period the larger the price deviation in the current period. Trading activity as measured by Volume has no significant effect, just as the number of risk-averse traders within a market (\# Risk Averse).

Turning to the effects of treatment features, we see that "bad"-state markets exhibit significantly larger price deviations then "good"-state markets, a non-surprising finding, consistent with the prior nonparametric analysis. 
Table 7: Relative and Absolute Deviation Measures

\begin{tabular}{|c|c|c|c|c|c|c|c|}
\hline \multicolumn{2}{|c|}{ Comparison by } & Nin & $\mathrm{NinB}$ & p-value & Tin & TinB & p-value \\
\hline \multirow{3}{*}{ Bayes $^{a}$} & $\mathrm{RD}$ & 0.058 & 0.074 & .8336 & 0.015 & 0.018 & .9164 \\
\hline & RAD & 0.291 & 0.195 & .0357 & 0.176 & 0.200 & .5286 \\
\hline & & Nin & Tin & p-value & $\mathrm{Nin} B$ & TinB & p-value \\
\hline \multirow{2}{*}{ Insider $^{\mathrm{a}}$} & $\mathrm{RD}$ & 0.058 & 0.015 & .8336 & 0.074 & 0.018 & .5286 \\
\hline & RAD & 0.291 & 0.176 & .0033 & 0.195 & 0.200 & .7527 \\
\hline \multicolumn{2}{|c|}{ Comparison by } & $\mathrm{Nin}+$ & Nin- & p-value & $\mathrm{NinB}+$ & NinB- & p-value \\
\hline \multirow{3}{*}{ State $^{\mathrm{b}}$} & $\mathrm{RD}$ & -0.202 & 0.319 & .0209 & -0.095 & 0.243 & .0209 \\
\hline & RAD & 0.242 & 0.339 & .0209 & 0.124 & 0.265 & .0433 \\
\hline & & Tin+ & Tin- & p-value & TinB+ & TinB- & p-value \\
\hline \multirow{3}{*}{ State $^{b}$} & $\mathrm{RD}$ & -0.097 & 0.128 & .0209 & -0.113 & 0.148 & .0433 \\
\hline & RAD & 0.149 & 0.203 & .1489 & 0.185 & 0.214 & .7728 \\
\hline & & $\mathrm{Nin}+$ & $\mathrm{NinB}+$ & $p$-value & Nin- & NinB- & p-value \\
\hline \multirow{3}{*}{ Bayes $^{b}$} & $\mathrm{RD}$ & -0.202 & -0.095 & .0833 & 0.319 & 0.243 & .2482 \\
\hline & RAD & 0.242 & 0.124 & .0209 & 0.339 & 0.265 & .2482 \\
\hline & & Tin+ & TinB+ & $\mathrm{p}$-value & Tin- & TinB- & p-value \\
\hline \multirow{3}{*}{ Bayes $^{b}$} & $\mathrm{RD}$ & -0.097 & -0.113 & .7728 & 0.128 & 0.148 & .5637 \\
\hline & RAD & 0.149 & 0.185 & .3865 & 0.203 & 0.214 & .7728 \\
\hline & & $\mathrm{Nin}+$ & Tin+ & p-value & Nin- & Tin- & p-value \\
\hline \multirow{3}{*}{ Insider $^{b}$} & $\mathrm{RD}$ & -0.202 & -0.097 & .0833 & 0.319 & 0.128 & .0209 \\
\hline & RAD & 0.242 & 0.149 & .0209 & 0.339 & 0.203 & .0209 \\
\hline & & $\mathrm{NinB}+$ & TinB+ & $\mathrm{p}$-value & NinB- & TinB- & p-value \\
\hline \multirow{2}{*}{ Insider ${ }^{b}$} & $\mathrm{RD}$ & -0.095 & -0.113 & .7728 & 0.243 & 0.148 & .3865 \\
\hline & RAD & 0.124 & 0.185 & .2482 & 0.265 & 0.214 & .3865 \\
\hline
\end{tabular}

Notes: Mann-Whitney U test, two-sided: ${ }^{\mathrm{a}} N=16(8 / 8),{ }^{\mathrm{b}} N=8(4 / 4)$.

The provision of BFVs has no effect in both states, when the utilized control variables are considered. This contradicts the nonparametric result. We do not expect that this lack of difference is caused by the fact that traders were actually able to calculate BFVs in the setting where they were not provided. But traders seem to be intuitively able to anticipate approximated BFVs. The presence of insiders is only significant, i.e., exerting a negative (price deviation decreasing) effect in "bad"-state markets, ${ }^{20}$ a finding that requires further analysis for a proper understanding.

We are able to calculate the treatment effects (coefficients), given that treatments are comprised of combinations of several features. These coefficients are presented in Table 9 in descending order in terms of the coefficient size. The calculated coefficients are equal to the ones that result out of a regression with treatments as dummy variables and Nin+ as baseline.

20 This outcome is, as explained later, driven by the fact that Nin+ and Tin+ markets are not statistically different. For NinB+ and TinB+ markets the presence of insiders is beneficial. 
Table 8: Regressions for RDs of Market Prices from Fundamentals

\begin{tabular}{|c|c|c|}
\hline Dependent Variable: $R D_{m t}$ & Model 1 & Model 2 \\
\hline Constant (Nin+) & $\begin{array}{c}6.30 \\
(5.01)\end{array}$ & $\begin{array}{c}-3.53 \\
(10.12)\end{array}$ \\
\hline L. $R D_{m t}$ & $\begin{array}{c}0.56^{* * *} \\
(0.05)\end{array}$ & $\begin{array}{c}0.57^{* * *} \\
(0.04)\end{array}$ \\
\hline Period & $\begin{array}{c}-1.15^{* * *} \\
(0.41)\end{array}$ & $\begin{array}{c}-1.20^{* * *} \\
(0.57)\end{array}$ \\
\hline Volume & $\begin{array}{c}0.13 \\
(0.27)\end{array}$ & $\begin{array}{c}0.10 \\
(0.26)\end{array}$ \\
\hline State (Nin-) & $\begin{array}{c}22.30^{* * *} \\
(7.03)\end{array}$ & $\begin{array}{c}25.38^{* * *} \\
(8.22)\end{array}$ \\
\hline Bayes (NinB+) & $\begin{array}{l}-4.75 \\
(4.08)\end{array}$ & $\begin{array}{l}-2.68 \\
(4.87)\end{array}$ \\
\hline Insiders (Tin+) & $\begin{array}{c}4.43 \\
(4.87)\end{array}$ & $\begin{array}{c}4.66 \\
(5.10)\end{array}$ \\
\hline State $\times$ Bayes & $\begin{array}{c}6.56 \\
(6.54)\end{array}$ & $\begin{array}{c}3.12 \\
(9.12)\end{array}$ \\
\hline State $\times$ Insiders & $\begin{array}{c}-16.39^{* *} \\
(7.93)\end{array}$ & $\begin{array}{l}-17.29^{*} \\
(10.09)\end{array}$ \\
\hline Bayes $\times$ Insiders & $\begin{array}{c}8.63 \\
(6.53)\end{array}$ & $\begin{array}{c}6.42 \\
(7.60)\end{array}$ \\
\hline State $\times$ Bayes $\times$ Insiders & $\begin{array}{l}-8.06 \\
(9.41)\end{array}$ & $\begin{array}{c}-3.05 \\
(12.98)\end{array}$ \\
\hline L. Dividend & & $\begin{array}{c}0.12^{* * *} \\
(0.04)\end{array}$ \\
\hline \# Risk Averse & & $\begin{array}{c}0.92 \\
(1.68)\end{array}$ \\
\hline$R^{2}$ & .7478 & .7534 \\
\hline$N$ & 247 & 247 \\
\hline \multicolumn{3}{|c|}{$\begin{array}{l}\text { Notes: Prais-Winsten panel-regression with heteroskedastic panels corrected standard errors and } \\
\text { panel-specific autocorrelation (AR1) (Beck and Katz 1995). } 32 \text { markets as cross sections with a } \\
\text { maximum of } 15 \text { observations over time (unbalanced). Only periods where trade took place are } \\
\text { considered. Standard errors are shown in parentheses. }{ }^{* *}, \text {, and }{ }^{* * *} \text { indicate significance at the } 10 \% \text {, } \\
5 \% \text {, and } 1 \% \text { levels, respectively. }\end{array}$} \\
\hline
\end{tabular}

Using these coefficients we are able to disentangle differences between treatments by conducting meaningful comparisons which consist of three comparisons for each treatment: (1) a comparison with the counterpart in the "bad"/"good" state, (2) a comparison with the counterpart where BFVs are/are not provided, and (3) a comparison with the counterpart where insiders are/are not present, respectively. We conduct Wald tests to test for the equality of estimated coefficients for these comparisons. The results can be retraced via Table 10, where all possible comparisons are shown and significant differences are highlighted as bold figures. 
Table 9: Treatment Effects on RDs of Market Prices from Fundamentals in Model 2

\begin{tabular}{cccc}
\hline Treatment & Effect of... & Coefficient & p-value \\
\hline NinB- & $S+B+S B$ & 25.82 & $\mathbf{. 0 0 0}$ \\
Nin- & $S$ & 25.38 & $\mathbf{. 0 0 2}$ \\
TinB- & $S+B+I+S B+S I+B I+S B I$ & 16.56 & $\mathbf{. 0 0 0}$ \\
Tin- & $S+I+S I$ & 12.75 & $\mathbf{. 0 0 4}$ \\
TinB+ & $B+I+B I$ & 8.40 & $\mathbf{. 0 6 2}$ \\
Tin+ & $I$ & 4.66 & .361 \\
Nin+ & --- & -3.53 & .727 \\
NinB+ & $B$ & -2.68 & .582 \\
\hline Notes: $S=$ State ("Bad"), $B=$ BFVs (provided), I = Insiders (present).
\end{tabular}

Our finding that "bad" state markets exhibit significantly larger price deviations then "good"-state markets is confirmed with the exception of Tin markets, where deviations in the "bad" state are larger, however, statistically insignificant. The result that the provision of BFVs has no effect is unambiguously confirmed. Moreover, as already seen, the presence of insiders significantly reduces price deviations in "bad"-state markets, leading to an improved market performance.

Furthermore, the presence of insiders leads to an increase of the deviation measure in the "good" state which, given that "good"-state markets tend to trade below fundamentals, leads to an improvement in market performance, i.e., deviations from FVs are smaller in absolute terms, when insiders are present; however, the difference between Nin+ and Tin+ is not significant. Thus, these findings confirm and broaden the prior findings of the nonparametric analysis.

Result 2: Bubbles occur but are infrequent. The nonparametric analysis indicates that the introduction of insiders reduces bubbles, measured by $R D$ and $R A D$, however, only when $B F V$ s are not provided. The provision with BFVs significantly reduces deviations, however, only when no insiders are present. The performance of markets where insiders are present and BFVs are given together is not distinguishable from markets where only one of these ingredients is at work. The panel analysis refines and demerges the previous results and indicates that the introduction of insiders improves market performance (measured by $R D_{m t}$ ) and that the provision of BFVs has no effect on market performance. 
Table 10: Wald Test for Differences of Treatment Coefficients in Model 2

\begin{tabular}{lcccccccc}
\hline & NinB+ & NinB- & TinB+ & TinB- & Nin+ & Nin- & Tin+ & Tin- \\
NinB+ & --- & $\mathbf{. 0 0 0}$ & $\mathbf{. 0 1 8}$ & $\mathbf{. 0 0 0}$ & .582 & $\mathbf{. 0 0 0}$ & .103 & $\mathbf{. 0 0 2}$ \\
NinB- & & --- & $\mathbf{. 0 0 1}$ & $\mathbf{. 0 3 2}$ & $\mathbf{. 0 0 0}$ & .942 & $\mathbf{. 0 0 0}$ & $\mathbf{. 0 0 3}$ \\
TinB+ & & & --- & $\mathbf{. 0 7 7}$ & $\mathbf{. 0 6 2}$ &. $\mathbf{0 2 7}$ & .469 & .364 \\
TinB- & & & & --- &. $\mathbf{0 0 0}$ & .175 & $\mathbf{. 0 1 6}$ & .379 \\
Nin+ & & & & & --- &. $\mathbf{0 0 2}$ & .361 & $\mathbf{. 0 0 4}$ \\
Nin- & & & & & & --- & $\mathbf{. 0 0 5}$ & $\mathbf{. 0 8 7}$ \\
Tin+ & & & & & & & --- & .134 \\
Tin- & & & & & & & & --- \\
\hline
\end{tabular}

Notes: p-values of Wald tests for the simple linear hypothesis of equality of estimated parameters are shown. Nin+ is the reference category. Bold figures show significant differences at the $10 \%$ level.

For the sake of completeness, Figure 3 presents the course of the average trading volumes conditioned on information and the provision of BFVs. Each curve represents the average over four markets, in the "good" or "bad" state, respectively. The trading volume shows a tendency to decline on average with market duration. Trading volumes do not to differ significantly between different treatment conditions.

Figure 3: Average Trading Volume
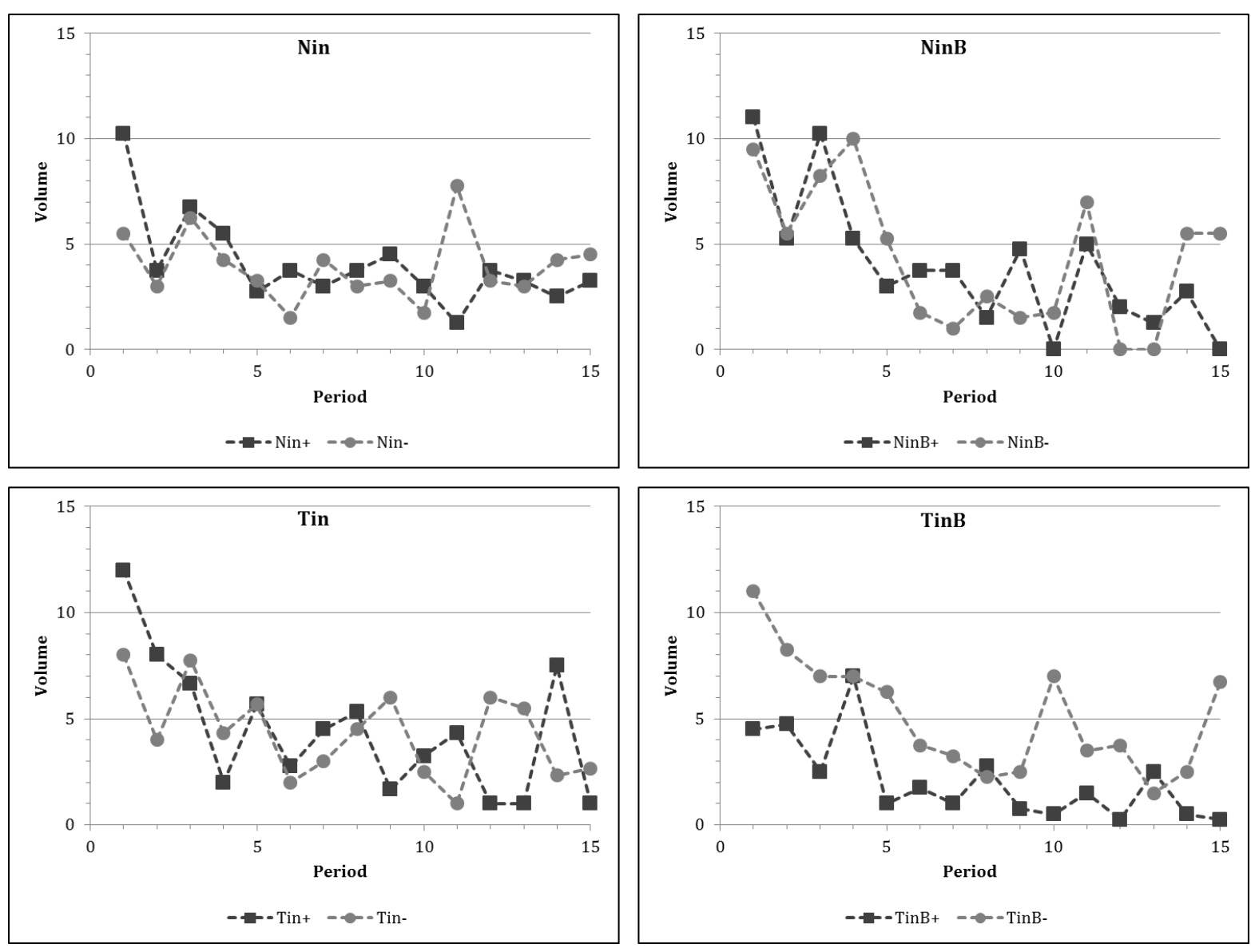


\subsection{Comparison of Insiders and Outsiders}

Following the investigation of overall trading patterns we now turn to the analysis of the trading behavior of in-and outsiders and explore Hypotheses 3 to 5. Figure 4 shows the course of average limit buy and sell order prices in the TinB and Tin markets. ${ }^{21}$ As can be seen, in- and outsider limit bids and limit asks differ but not substantially. Limit buy and sell order prices only differ clearly in the first period(s) of the TinB- and Tin+ markets. In these cases both prices are lower for insiders in the TinB- markets (in the case of limit sell order prices "irrationally" low) and higher in the Tin+ markets, respectively. Furthermore, the following general patterns are visible. Firstly, both trader types, on average, want to pay less when buying and ask higher prices when selling assets compared to the actual FV in the TinB+ and Tin+ markets. Secondly, both trader types, on average, want to pay approximately the FV to buy assets but ask more than the actual FV to sell assets in the TinB- and Tin- markets.

Result 3: Trading behavior of uninformed traders at the beginning differs from that of informed traders but converges with the market price during the market toward that of informed traders. Uninformed traders are able to grasp the correct state and to trade accordingly to it.

We continue our analysis with nonparametric statistical tests on first-period bid and ask behavior of in- and outsiders, measured by limit buy/sell order prices and quantities. First-period behavior of outsiders does not differ between the two states (using twosided U tests), whether BFVs are provided or not. In other words, the starting positions of outsider bid and ask prices and quantities are the same in the "good" and "bad" state. First-period behavior of insiders, on the contrary, differs significantly between the two states, with higher bid/ask prices in the "good" state, and also larger bid/ask quantities, when BFVs are not provided (see Table A. 5 in Appendix A).

Comparing first-period behavior between in- and outsiders, we find outsider limit buy/sell order prices to be higher in TinB- markets and insider limit buy order prices and sale quantities to be higher in the Tin+ markets (using two-sided $U$ tests). The differences in buy/sell order prices and quantities in TinB+ and Tin- markets are insignificant (see also Table A. 5 in Appendix A).

To identify overall differences in the buying and selling behavior of in-and outsiders, we conduct panel-regressions with traders as cross sections $(i=1, \ldots, 192)$. The dependent variable used is again derived from the RD measure (Stöckl et al. 2010), denoted in percent, and is defined as:

$$
R D_{i t}^{D, S}=\frac{p_{i t}^{D, S}-F V_{t}}{\overline{F V}}
$$

\footnotetext{
${ }^{21}$ Figures A. 1 and A. 2 in Appendix A additionally exhibit the average limit buy and sell prices of the Nin(B) and Tin(B) markets, whereby for the latter prices are averaged over both in- and outsiders.
} 
where $R D_{i t}^{D, S}$ measures the difference between the individual limit buy/sell order prices of period $\mathrm{t}\left(p_{i t}^{D, S}\right)$ and the respective fundamental value $\left(F V_{t}\right)$, normalized by the average fundamental value $(\overline{F V})$.

We control for trader type effects by using dummy variables for the trader types under all treatment conditions (resulting in Nin+ Outsider as the reference type). Additionally, we control for autocorrelation by inclusion of the dependent variable with a lag of one period (L. RD), for a time trend within markets by inclusion of a period variable (Period), for the bid/ask quantity (Order Quantity), for the amount of assets held in the portfolio (Asset Holdings), and for the trading activity in the previous period (L. Bought Assets, L. Sold Assets). Furthermore, we include the drawn dividend of the prior period (L. Dividend), a variable that measures the individually perceived understanding of the market (Market Understanding, elicited in the ex-post questionnaire, ranging from 0 to 10), a variable that measures individual risk aversion (Risk Aversion) (elicited following the approach of Holt and Laury (2002), ranging from -3 to 5), and Gender (with women as reference category) as explanatory variables. The results are shown in Table 11. Given the similar results for each of both dependent variables, we focus our analysis respectively on the augmented Models 4 and 6 .

The regression results for Model 4 show that bid price deviations (measured by $R D_{i t}^{p^{D}}$ ) are path-dependent; $L . R D$ has a significantly positive effect. Traders bid more eagerly in later periods; Period has a significantly positive effect on bid prices. Traders are cautious when buying, the higher the bid quantity, the lower the bidding price; Order Quantity $\left(q_{i t}^{D}\right)$ has a significantly negative effect. Current asset holdings (in the portfolio) and the quantity of sold assets in the prior period do not have an influence; Asset Holdings and L. Sold Assets are insignificant. Previous buying success, however, reduces bid prices; L. Bought Assets has a significantly negative effect. The dividend drawn in the previous period has a slight price boosting effect, the higher the dividend in the previous period the larger the bid price in the current period; L.Dividend is significantly positive. Individual Market Understanding and Risk Aversion have significantly negative effects on bid prices. Male traders bid higher prices compared to women; Gender is significantly positive.

Comparing the bid prices of in- and outsiders, we see that on average insiders bid higher prices in the Tin+ and TinB+ markets and lower prices in the Tin- and TinB- markets. All differences are significant, except for TinB- (see Table 12). 
Figure 4: Insider and Outsider Limit Buy Order and Limit Sell Order Prices
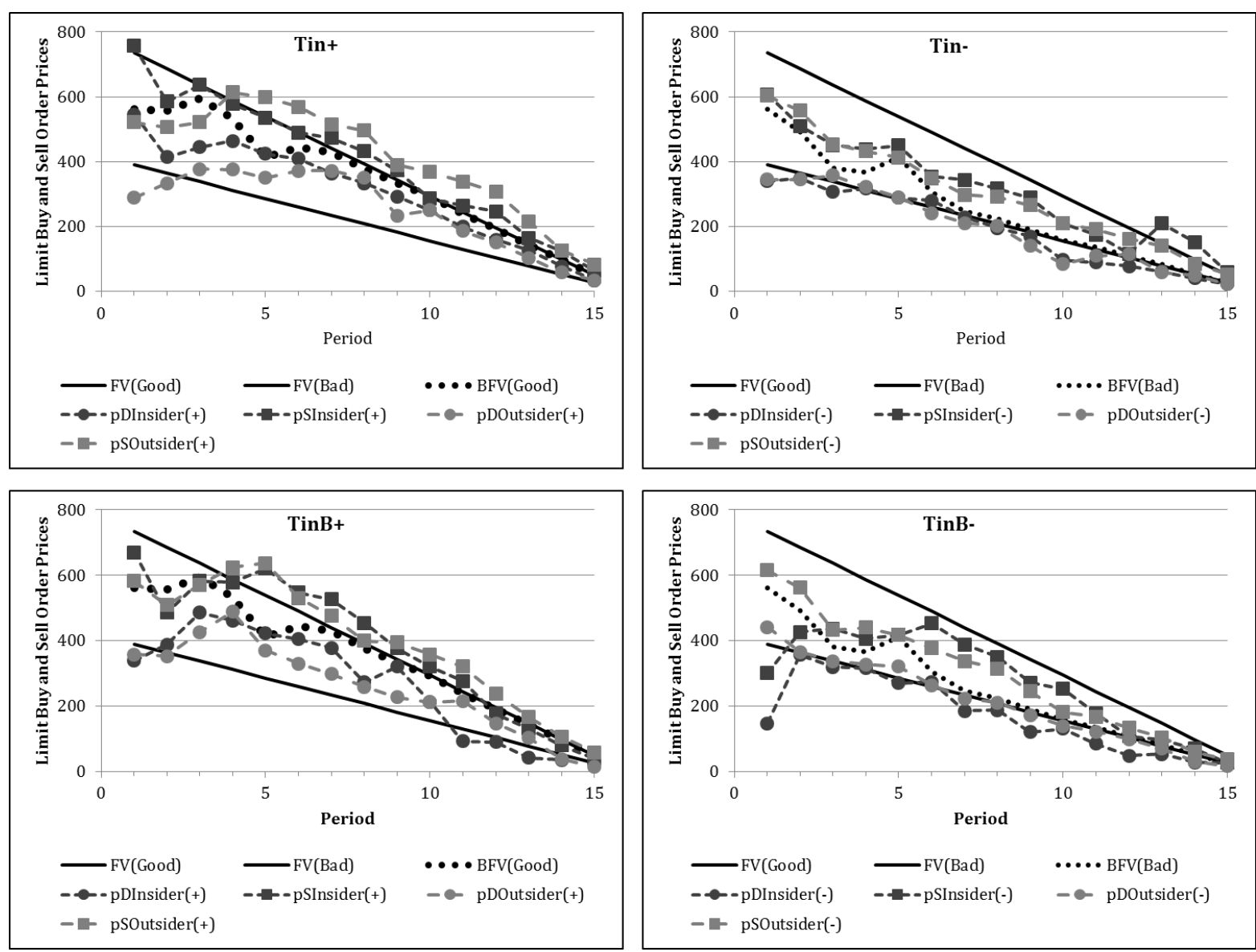

The regression results for Model 6 show that ask prices (measured by $R D_{t}^{p^{S}}$ ) are strongly path-dependent (more path-dependent than bid prices); $L . R D$ has a significantly positive effect. Traders are satisfied with lower ask prices in later periods; Period has a significantly negative effect. Traders seem not to be as cautious with regard to their portfolio when selling; Order Quantity $\left(q_{i t}^{S}\right)$ and current Asset Holdings do not to have a significant effect. On the other hand, previous buying success reduces ask prices, L. Bought Assets is significantly negative, and previous sale success increases bid prices, L. Sold Assets is significantly positive. The dividend drawn in the previous period again has a slight price boosting effect on the ask price in the current period; L. Dividend is significantly positive. Individual Market Understanding, Risk Aversion, and Gender have no significant effects on ask prices.

Looking at the comparison of ask prices between in- and outsiders we see that on average insiders ask higher prices in the Tin+, TinB+, and TinB- markets and lower prices in the Tin- markets. However, the differences are only significant for Tin+ and Tin- markets (see Table 12). 
Table 11: Regressions for RDs of Limit Buy and Sell Prices from Fundamentals

\begin{tabular}{|c|c|c|c|c|}
\hline Dependent Variable: & $\begin{array}{c}\text { Model } 3 \\
R D_{i t}^{p^{D}}\end{array}$ & $\begin{array}{c}\text { Model } 4 \\
R D_{i t}^{p^{D}}\end{array}$ & $\begin{array}{c}\text { Model } 5 \\
R D_{i t}^{p^{S}}\end{array}$ & $\begin{array}{c}\text { Model 6 } \\
R D_{i t}^{p^{s}} \\
\end{array}$ \\
\hline Constant (Nin+ Outsider) & $\begin{array}{c}-18.53^{* * *} \\
(6.23)\end{array}$ & $\begin{array}{c}-5.78 \\
(10.14)\end{array}$ & $\begin{array}{l}7.47^{* *} \\
(3.06)\end{array}$ & $\begin{array}{c}23.40^{* * *} \\
(7.64)\end{array}$ \\
\hline L. $R D_{i t}^{p^{D, S}}$ & $\begin{array}{c}0.32^{* * *} \\
(0.06)\end{array}$ & $\begin{array}{c}0.31^{* * *} \\
(0.06)\end{array}$ & $\begin{array}{c}0.56^{* * * *} \\
(0.03)\end{array}$ & $\begin{array}{c}0.56^{* * *} \\
(0.03)\end{array}$ \\
\hline Period & $\begin{array}{l}0.65^{*} \\
(0.34)\end{array}$ & $\begin{array}{c}0.62^{*} \\
(0.33)\end{array}$ & $\begin{array}{c}-0.72^{* * *} \\
(0.24)\end{array}$ & $\begin{array}{c}-0.72^{* * *} \\
(0.24)\end{array}$ \\
\hline Order Quantity $\left(q_{i t}^{D}, q_{i t}^{S}\right)$ & $\begin{array}{c}-0.63^{* * *} \\
(0.12)\end{array}$ & $\begin{array}{c}-0.73^{* * *} \\
(0.13)\end{array}$ & $\begin{array}{l}-0.12 \\
(0.23)\end{array}$ & $\begin{array}{l}-0.11 \\
(0.22)\end{array}$ \\
\hline Asset Holdings & $\begin{array}{l}-0.14 \\
(0.18)\end{array}$ & $\begin{array}{c}-0.25 \\
(0.17)\end{array}$ & $\begin{array}{l}-0.12 \\
(0.23)\end{array}$ & $\begin{array}{c}0.01 \\
(0.20)\end{array}$ \\
\hline L. Bought Assets & $\begin{array}{c}-2.17^{* * *} \\
(0.36)\end{array}$ & $\begin{array}{c}-2.17^{* * *} \\
(0.36)\end{array}$ & $\begin{array}{c}-1.20^{* * *} \\
(0.39)\end{array}$ & $\begin{array}{c}-1.08^{* * *} \\
(0.38)\end{array}$ \\
\hline L. Sold Assets & $\begin{array}{c}-0.13 \\
(0.46)\end{array}$ & $\begin{array}{l}-0.18 \\
(0.45)\end{array}$ & $\begin{array}{c}2.36^{* * *} \\
(0.46)\end{array}$ & $\begin{array}{c}2.55^{* * * *} \\
(0.46)\end{array}$ \\
\hline Nin-Outsider & $\begin{array}{c}41.83^{* * *} \\
(7.08)\end{array}$ & $\begin{array}{c}43.75^{* * *} \\
(7.18)\end{array}$ & $\begin{array}{c}25.94^{* * *} \\
(4.52)\end{array}$ & $\begin{array}{c}26.12^{* * *} \\
(4.31)\end{array}$ \\
\hline $\mathrm{NinB}+$ Outsider & $\begin{array}{l}9.68^{* *} \\
(3.90)\end{array}$ & $\begin{array}{c}10.12^{* *} \\
(4.05)\end{array}$ & $\begin{array}{c}-0.17 \\
(2.76)\end{array}$ & $\begin{array}{c}0.09 \\
(3.09)\end{array}$ \\
\hline NinB-Outsider & $\begin{array}{c}37.68^{* * * *} \\
(6.84)\end{array}$ & $\begin{array}{c}38.47^{* * *} \\
(6.94)\end{array}$ & $\begin{array}{c}25.18^{* * *} \\
(4.42)\end{array}$ & $\begin{array}{c}24.84^{* * *} \\
(4.55)\end{array}$ \\
\hline Tin+ Insider & $\begin{array}{c}4.63 \\
(4.59)\end{array}$ & $\begin{array}{c}10.77^{* *} \\
(5.13)\end{array}$ & $\begin{array}{c}1.61 \\
(2.77)\end{array}$ & $\begin{array}{c}5.04 \\
(3.21)\end{array}$ \\
\hline Tin + Outsider & $\begin{array}{c}3.29 \\
(3.91)\end{array}$ & $\begin{array}{c}1.14 \\
(4.13)\end{array}$ & $\begin{array}{l}-0.49 \\
(2.93)\end{array}$ & $\begin{array}{l}-3.38 \\
(3.21)\end{array}$ \\
\hline Tin- Insider & $\begin{array}{c}14.36^{* * *} \\
(4.68)\end{array}$ & $\begin{array}{c}13.15^{* * *} \\
(4.89)\end{array}$ & $\begin{array}{c}5.77 \\
(4.39)\end{array}$ & $\begin{array}{c}0.82 \\
(4.82)\end{array}$ \\
\hline Tin-Outsider & $\begin{array}{c}20.65^{* * *} \\
(5.06)\end{array}$ & $\begin{array}{c}21.88^{* * *} \\
(5.40)\end{array}$ & $\begin{array}{c}9.63^{* * *} \\
(3.42)\end{array}$ & $\begin{array}{c}9.25^{* * *} \\
(3.59)\end{array}$ \\
\hline TinB+ Insider & $\begin{array}{c}9.31^{*} \\
(4.91)\end{array}$ & $\begin{array}{c}10.35^{* *} \\
(5.13)\end{array}$ & $\begin{array}{c}1.46 \\
(2.82)\end{array}$ & $\begin{array}{c}0.66 \\
(3.06)\end{array}$ \\
\hline TinB+ Outsider & $\begin{array}{c}0.53 \\
(4.04)\end{array}$ & $\begin{array}{l}-2.92 \\
(4.83)\end{array}$ & $\begin{array}{c}0.33 \\
(2.85)\end{array}$ & $\begin{array}{l}-1.83 \\
(2.86)\end{array}$ \\
\hline TinB-Insider & $\begin{array}{c}24.66^{* * *} \\
(7.95)\end{array}$ & $\begin{array}{c}22.87^{* * * *} \\
(8.16)\end{array}$ & $\begin{array}{c}17.44^{* * *} \\
(4.48)\end{array}$ & $\begin{array}{c}15.62^{* * *} \\
(4.81)\end{array}$ \\
\hline TinB-Outsider & $\begin{array}{c}26.44^{* * *} \\
(5.79)\end{array}$ & $\begin{array}{c}25.60^{* * *} \\
(5.80)\end{array}$ & $\begin{array}{c}10.91^{* *} \\
(5.31)\end{array}$ & $\begin{array}{l}9.62^{*} \\
(5.40)\end{array}$ \\
\hline L. Dividend & & $\begin{array}{c}0.05^{*} \\
(0.03)\end{array}$ & & $\begin{array}{l}0.07^{* *} \\
(0.03)\end{array}$ \\
\hline Market Understanding & & $\begin{array}{c}-2.98^{* *} \\
(1.29)\end{array}$ & & $\begin{array}{l}-3.69 \\
(1.13)\end{array}$ \\
\hline Risk Aversion & & $\begin{array}{c}-1.57^{* * *} \\
(0.51)\end{array}$ & & $\begin{array}{l}-0.34 \\
(0.53)\end{array}$ \\
\hline Gender (Male) & & $\begin{array}{l}8.16^{* * *} \\
(2.45)\end{array}$ & & $\begin{array}{c}0.05 \\
(1.99)\end{array}$ \\
\hline$R^{2}$ & .3961 & .4131 & .6099 & .6170 \\
\hline$N$ & 1597 & 1597 & 1742 & 1742 \\
\hline
\end{tabular}


Table 12: Wald Tests for Differences of Treatment Coefficients in Models $4 \& 6$

\begin{tabular}{ccc}
\hline & \multicolumn{2}{c}{ Insider vs. Outsider } \\
Treatment & $\overline{\mathrm{p}}^{\mathrm{D}}$ & $\overline{\mathrm{p}}^{\mathrm{S}}$ \\
(State Label) & $(4)$ & $(6)$ \\
\hline Tin+ & $\mathbf{. 0 2 9 1 ( > )}$ & $\mathbf{. 0 2 8 0 ( > )}$ \\
Tin- & $\mathbf{. 0 4 5 9 ( < )}$ & $\mathbf{. 0 7 0 4 ( < )}$ \\
TinB+ & $\mathbf{. 0 0 8 0}(>)$ & .4158 \\
TinB- & .7135 & .3083 \\
\hline
\end{tabular}

Notes: p-values of Wald tests for the simple linear hypothesis of equality of estimated parameters are shown.

Aggregating the results for limit bid/ask prices we conclude that, particularly in the beginning of the markets, insiders are the traders which tend to buy assets in the "good" state, when assets are relatively cheaply sold by outsiders and sell assets in the "bad" state, when they are relatively expensively bought by outsiders. Given this conclusion it is not surprising that asset holdings of in- and outsiders indeed differ significantly between "good"-state and "bad"-state markets, at least in the beginning of the markets, as it is theoretically predicted by both informational models (PI and RE).

In the "good"-state markets, insiders are those traders that hold on average more assets during the entire markets and significantly more during the first six periods. In the "bad"-state markets outsiders are those traders that hold on average more assets during the entire markets and significantly more during periods 3 to 13 . All differences are significant at the 5-10\% level, using the Wilcoxon matched pairs signed-rank test, $N=16$ (8/8). Insiders are thus capable of using their superior informational position and buy relatively underpriced assets in the "good" state and sell relatively overpriced assets in the "bad" state. However, it should be noted that asset stocks of in- and outsiders align during the course of the markets in both states.

Result 4: Insiders are those traders that hold more assets in the "good"-state markets and outsiders are those traders that hold more assets in the "bad"-state markets.

Furthermore a concentration of assets at single players over the course of the markets is evident. Over all markets the trader with the largest asset portfolio in one market holds on average 27.2 assets (with a standard deviation of 6.298) at the end of period 15 . Concentration, however, is not automatically equated with a more remunerative trading strategy of the "hoarding" traders. Although, in eleven markets those traders which held the largest asset stock also earned the highest net-profit (total profit minus prediction earnings), a significant correlation cannot be detected between the asset stock of a trader at the end of a market and her/his net-profit. The Spearman's rank correlation coefficient is $\rho=.0263$ (p-value $=.7174)$. 
Although the behavior of in- and outsiders converges, insiders are able to benefit from their superior informational position. Insiders on average earn higher total profits in Tin+, Tin-, TinB+, and TinB- markets, though the difference to outsiders is only significant for Tin+ (see Table A. 6 in Appendix A). Aggregated over all treatments with informational asymmetry, insiders earn significantly higher total profits (6346 ECU vs. 5565 ECU, two-sided t-test, p-value $=.0793, N=96,32 / 64$ ).

Result 5: Informed traders have a trading advantage that is revealed in superior profits. Summarized our data definitively indicates that traders in Tin(B) markets didn't incur what Camerer et al. (1989) call the "curse of knowledge".

Markets are not strong-form efficient, following the definition of Fama (1970), because insiders are able to earn "abnormal returns" from trading on the basis of their private (insider) information. This result supports the findings of Jaffe (1974).

\subsection{Beliefs and Market Prices}

Since optimal trading actions depend on beliefs about other players' decisions, which again depend on the beliefs of actions of others etc. (Palfrey and Wang 2009), ${ }^{22}$ we examine if stated beliefs on the market price are informative about the actual market price. We investigate to what extent elicited price expectations and actual market prices are correlated. Furthermore, we are interested in how expectations change if the available information and distribution of information changes.

We are aware that belief elicitation can alter decisions in the experiment. Gächter and Renner (2010) for example have shown that incentivized belief elicitation about contributions of others leads to higher contributions in a public-good experiment. However, the experimental asset markets investigated by Haruvy et al. (2007), who elicited beliefs about market prices in the same way as we do, closely resemble markets of previous studies without belief elicitation. Thus, we do not expect a large manipulation.

In the beginning of each period, participants were required to state their expectations about the prospective market prices of the present and all subsequent trading periods. In the following we denote the elicited beliefs in the form: $B_{t}^{f}$, where $t$ denotes the period of elicitation, i.e., the period in which traders were asked to submit their price beliefs and $f$ denotes the period forecasted, i.e., the period for which the price beliefs are stated.

Figure 5 shows the average predicted price levels by treatment. Each bar in all eight graphs represents the average of four markets, i.e., 24 traders. Figure A. 3 in the

22 "In a world of uncertainty "fundamentals" get replaced by expectations about fundamentals" (Sunder 1995, p. 468). 
appendix illustrates the associated between-subject standard deviations of the marketprice predictions. As can be seen, traders' expectations about the price trajectory contain the belief of declining prices as theoretically prescribed by fundamentals. This indicates that fundamentals are clearly interpreted as the expected value of the future dividend stream, as emphasized in the experimental instructions. In contrast to (Lei et al. 2001), in our framework, a common dividend, and common knowledge thereof, seems to be sufficient to induce initial common expectations that are consistent with fundamentals. In contrast, traders in Haruvy et al. (2007) anticipated a flat price trajectory at the beginning, followed by an increasing trajectory in the middle, and a declining trajectory toward the end of the first round of their experiment. Our findings resemble their markets with most experienced traders. ${ }^{23}$

Individual beliefs for the first period $\left(B_{1}^{1}\right)$ start under almost all conditions around the $\mathrm{BFV}$ in the $1^{\text {st }}$ period, which is 563 . A t-test for the null hypothesis of no difference shows only for Tin a significant difference, where the average is 465.7 ( $\mathrm{p}$-value $=.0036, N=48$ ), compared to 547.4, 528.6, and 552.9 for NinB, TinB, and Nin respectively. Price assessments do not differ significantly by state within equal treatment conditions.

Within the insider treatments with and without the provision of BFVs we find that insider $B_{1}^{1}$ are respectively significantly higher for the "good" state compared to the "bad" state (U tests, $N=16: 587.9$ vs. 296.6, p-value $=.0098 ; 596.5$ vs. 488.8 , pvalue $=.0712$ ). Outsider beliefs on the other hand are, as we would expect, not significantly different between both states (U tests, $N=32$ : 548.2 vs. 595.4, pvalue $=.4677 ; 431.4$ vs. $423.1, \mathrm{p}$-value $=.7773$ ), though clearly different with and without the provision of BFVs.

Applying our convergence measure defined in Section 4.1 on the average last belief for each period $\left(\bar{B}_{t}^{t}\right)$, we find that beliefs converge more slowly toward fundamentals than market prices. We find 21 out of three markets not to converge, compared to ten markets for prices. Convergence time is slower for all treatments, though the difference is only significant for Tin (Wilcoxon signed-rank test, p-value $=.0487$ ). This result is consistent with the findings of Haruvy et al. (2007) when traders had some experience. Comparing the RD and RAD measures for last beliefs $\left(B_{t}^{t}\right)$ and market prices we find that RD shows only a significant difference between beliefs and market prices in NinB, where it is larger for prices, while the RAD measure is significantly larger for beliefs in NinB, TinB, and Tin markets (Wilcoxon signed-rank test, respective p-values: .0687, .0251, and .0357). It seems that positive and negative deviations cancel out each other in RD for both, beliefs and prices, but that deviations are absolutely larger for beliefs as revealed by RAD. Markets seem to exert a kind of synergy effect on traders' beliefs that help prices to converge faster to the rational expectations equilibrium than beliefs. To further test whether better market-price predictions in a market, measured by the average total prediction earnings in a market, lead to lower price deviations from fundamentals, measured by RD and RAD, we use a Spearman correlation test. We find a negative,

${ }^{23}$ Participants in Haruvy et al. (2007) played four markets, consisting of 15 periods each, in a row. 
however insignificant relation for $\mathrm{RD}(\rho=-.1850$, $\mathrm{p}$-value $=.3108)$, but a significantly negative correlation for $\operatorname{RAD}(\rho=-.3082$, $\mathrm{p}$-value $=.0862)$. Better predictions thus seem to lower price deviations.

Since the most important characteristic of forecasts or predictions is their correctness we now turn to the ability of forecasts to make inferences about future prices. To estimate the informational content contained in predictions of traders, we first estimate if and how the price level and the average belief about the market price are "correlated", using the following model:

$$
P_{m t}=\alpha+\beta \bar{B}_{m t}^{t}+\gamma X+\epsilon_{t},
$$

where $P_{t}$ is the market price in period $\mathrm{t}, \bar{B}_{t}^{t}$ is the average stated belief for the market price of period $t$ in period $t . X$ is a vector of further explanatory variables, containing treatment dummies, a period variable (Period), and the drawn dividend in the prior period (L. Dividend). If short-term expectations of market prices are unbiased, then $\alpha=$ $0, \beta=1$, and $\gamma=0$ are the expected coefficients.

Furthermore, to test the correctness of average trader beliefs concerning the anticipation of the market price, we estimate the following model:

$$
\frac{\bar{B}_{m t}^{t}-P_{m t}}{P_{m t}}=\alpha+\beta\left(\frac{\bar{B}_{m t-1}^{t-1}-P_{m t-1}}{P_{m t-1}}\right)+\gamma X+\epsilon_{t},
$$

where $\left(\bar{B}_{t}^{t}-P_{t}\right) / P_{t}$ denotes the deviation of the average belief in a market from the market price, relative to the market price. $\left(\bar{B}_{t-1}^{t-1}-P_{t-1}\right) / P_{t-1}$ is simply the one-period lag of the dependent variable and $\mathrm{X}$ is defined as above. If short-term expectations are unbiased, i.e., correct, then $\alpha=0, \beta=0$, and $\gamma=0$ are the expected coefficients.

The regression results of both models are shown in Models 7 and 8 in Table 13. As can be seen from Model 7 price expectations and actual market prices are strongly "correlated" with a highly significant coefficient of 0.9 , which is however significantly different from one $(\beta \neq 1$, $\mathrm{p}$-value $=.0011)$. Model 8 shows that the forecast quality, i.e., the relative deviation of beliefs from market prices, is not auto-correlated since $\beta$ is not statistically different from zero. Moreover, as it seems, the presence of insiders rather impedes forecast precision than enhances it. The three largest (negative) deviations in absolute terms, which hint on an underestimation of market prices, are all attributed to treatments where insiders were present (TinB+, Tin+, and Tin-). 
Figure 5: Average Predicted Market Prices
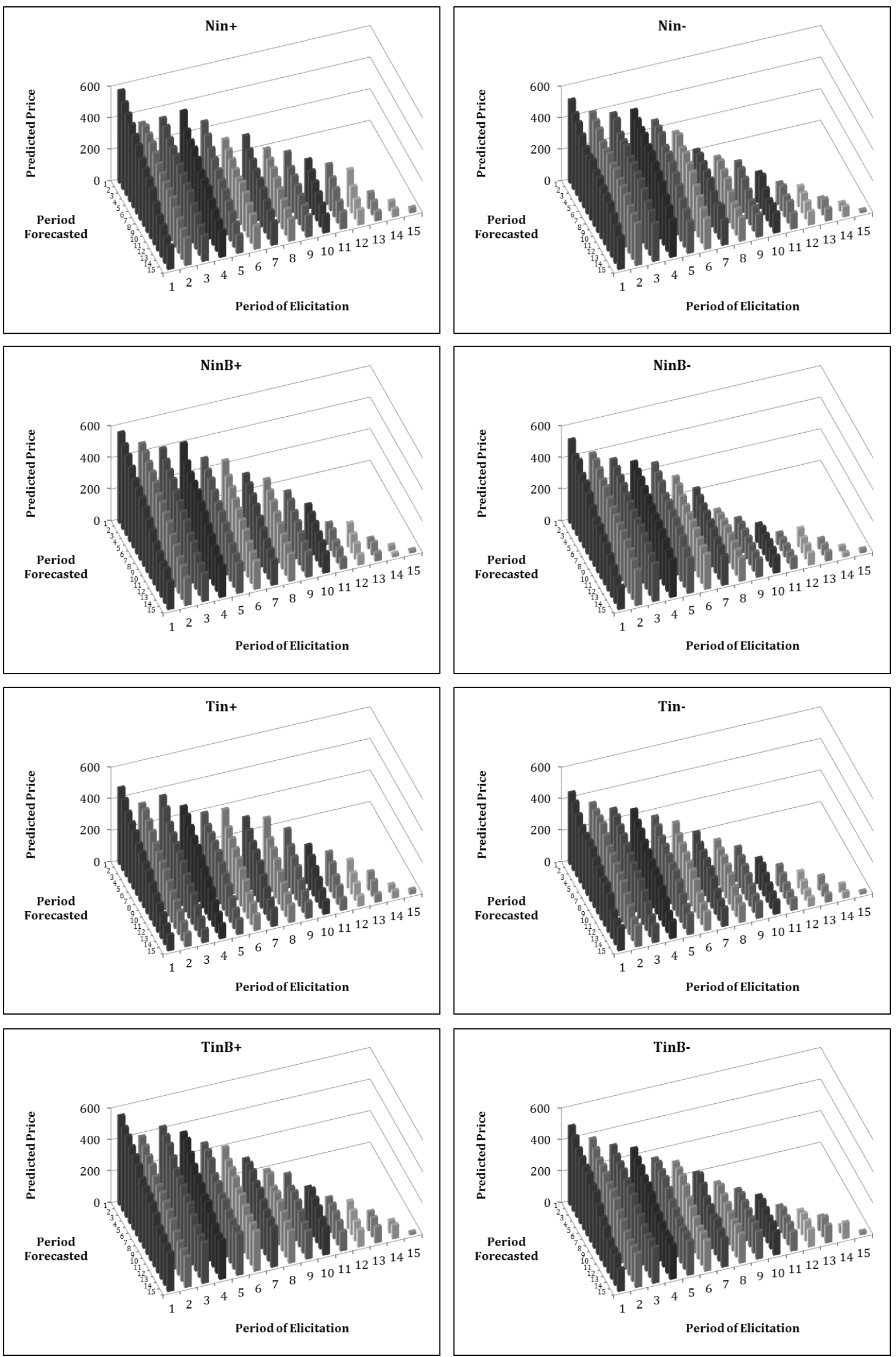
This finding seems to be driven by the outsiders in the Tin(B) markets and is supported by the following: On aggregate over all treatments with informational asymmetry, we find a significant difference in prediction earnings between in- and outsiders (144.9 ECU vs. 115.3 ECU, two-sided t-test, p-value $=.0735, N=96,32 / 64) .{ }^{24}$ Prediction earnings of outsiders in the Nin(B) markets are, however, not significantly different from earnings of insiders in the Tin(B) markets, but also significantly larger than prediction earnings of outsiders in the Tin(B) markets (137.0 ECU vs. 115.3 ECU, two-sided t-test, pvalue $=.0562, N=160,96 / 64$ ). The presence of insiders thus seems to psychologically impede the prediction ability of outsiders in the Tin(B) markets. This finding is consistent with Lovaglia et al. (1998), who found that a randomly assigned lower status impedes performance in a test of mental ability.

Given that the maximum possible amount for prediction earnings is $600 \mathrm{ECU}$, if all predictions lie in a range of $\pm 10 \%$ of the market price, prediction earnings of both trader types are quite bad and quite close to another, with a mean of $125.2 \mathrm{ECU}$, a standard deviation of $76.3 \mathrm{ECU}$, and a minimum and maximum of 0 ECU and 396 ECU over all 192 traders, respectively. Thus no pertinent differences can be found in a regression of market prices on individual beliefs. Nevertheless, although the difference is not large, it indicates that the trading advantage of insiders is at least partially conveyed in a better ability to anticipate market prices.

Result 6: Elicited price expectations and actual market prices are highly correlated. However, forecast quality (precision of beliefs) seems rather to be impeded by the presence of insiders. The provision of BFVs seems to have no impact on forecast quality.

To test whether better predictors also earn higher total trading profits (total profits corrected for prediction earnings) we use a Spearman correlation test. Over all 196 traders we find a highly significant connection between individual prediction quality and trading profits $(\rho=.2717$, p-value $=.0001)$. As we would expect, better predictors have more success in the market.

Additionally, we found men to make significantly higher earnings for predictions compared to women (139.5 vs. 118.5 , two-sided t-test, p-value $=.0432, N=192$, $113 / 79)$ and higher total trading profits, though here the difference is not significant (5800 vs. 5559, two-sided t-test, $p$-value $=.4362, N=192,113 / 79$ ). Alike, master students make significantly higher earnings for predictions compared to Bachelor students (151.4 vs. 124.9 , two-sided t-test, p-value $=.0319, N=181,42 / 139$ ) and also earn higher total trading profits (6372 vs. 5430, two-sided t-test, p-value $=.0106$, $N=181,42 / 139$ ).

\footnotetext{
${ }^{24}$ When Tin+, Tin-, TinB+, and TinB- markets are considered separately (see Table A. 6 in Appendix A), we find insiders to be slightly better predictors and earn on average higher prediction earnings, however the difference to outsiders is not significant.
} 
Table 13: Belief Regressions

\begin{tabular}{|c|c|c|}
\hline Dependent Variable & $\begin{array}{c}\text { Model } 7 \\
P_{m t}\end{array}$ & $\begin{array}{c}\text { Model 8 } \\
\left(\bar{B}_{m t}^{t}-P_{m t}\right) / P_{m t}\end{array}$ \\
\hline Constant (Nin+) & $\begin{array}{c}21.59 \\
(15.35)\end{array}$ & $\begin{array}{c}3.08 \\
(5.60)\end{array}$ \\
\hline $\bar{B}_{m t}^{t}$ & $\begin{array}{l}0.90^{* * *} \\
(0.03)\end{array}$ & \\
\hline$\left(\bar{B}_{m t-1}^{t-1}-P_{m t-1}\right) / P_{m t-1}$ & & $\begin{array}{l}-0.02 \\
(0.05)\end{array}$ \\
\hline Period & & $\begin{array}{c}0.56 \\
(0.36)\end{array}$ \\
\hline L. Dividend & $\begin{array}{l}0.29^{* *} \\
(0.13)\end{array}$ & $\begin{array}{l}-0.04 \\
(0.04)\end{array}$ \\
\hline $\mathrm{NinB+}$ & $\begin{array}{c}52.77^{* * *} \\
(17.91)\end{array}$ & $\begin{array}{l}-3.82 \\
(4.76)\end{array}$ \\
\hline$N i n B-$ & $\begin{array}{l}47.04^{* *} \\
(19.04)\end{array}$ & $\begin{array}{l}-9.22^{*} \\
(5.12)\end{array}$ \\
\hline TinB+ & $\begin{array}{l}40.51^{* *} \\
(19.45)\end{array}$ & $\begin{array}{c}-12.88^{* *} \\
(5.53)\end{array}$ \\
\hline TinB- & $\begin{array}{c}3.21 \\
(13.43)\end{array}$ & $\begin{array}{l}-2.09 \\
(5.13)\end{array}$ \\
\hline Nin- & $\begin{array}{c}12.47 \\
(17.45)\end{array}$ & $\begin{array}{l}-9.65^{*} \\
(5.21)\end{array}$ \\
\hline Tint & $\begin{array}{c}71.08^{* * *} \\
(18.89)\end{array}$ & $\begin{array}{c}-22.26^{* * *} \\
(5.56)\end{array}$ \\
\hline Tin- & $\begin{array}{c}-7.62 \\
(13.08)\end{array}$ & $\begin{array}{c}-10.34^{*} \\
(6.12)\end{array}$ \\
\hline$R^{2}$ & .8746 & .1450 \\
\hline$N$ & 315 & 247 \\
\hline \multicolumn{3}{|c|}{$\begin{array}{l}\text { Notes: Prais-Winsten panel-regression with heteroskedastic panels corrected } \\
\text { standard errors and panel-specific autocorrelation (AR1) (Beck and Katz 1995). } \\
32 \text { markets as cross sections with a maximum of } 15 \text { observations over time } \\
\text { (unbalanced). Only periods where trade took place are considered. Standard } \\
\text { errors are shown in parentheses. }{ }^{* *} \text {, and }{ }^{* * *} \text { indicate significance at the } 10 \% \text {, } \\
5 \% \text {, and } 1 \% \text { levels, respectively. }\end{array}$} \\
\hline
\end{tabular}




\section{Conclusion}

Our study investigates price formation in a multi-period asset market with uncertainty about market fundamentals. This novel framework combines the SSW environment with a "state-environment" investigated by, for example, Camerer and Weigelt (1991). It represents a "more realistic" market, although we are aware that real-life markets are not only characterized by uncertainty but also by ambiguity. In this newly designed uncertain SSW environment, we investigate whether (1) the existence of traders who are informed about the true state and/or (2) the provision of Bayesian updates of the assets' state-dependent fundamental values lead to better market performance.

Our results differ from earlier studies in that we hardly find any bubbles under all treatment conditions, even though all subjects were inexperienced. Out of 32 markets only four reveal a bubble pattern. Our explanation is that possibly the two possible states exert a psychologically restraining effect on market prices and force participants to more carefully reflect on their trading decisions.

We find markets with asymmetrically informed traders to exhibit smaller price deviations from fundamentals, implying higher market efficiency. This result is consistent with the findings of Sutter et al. (2012), and is most likely attributed to the fact that uninformed traders act in a more prudent way to bypass exploitation, when they are aware of the fact that some traders have an advantage (of whatever kind).

The provision of BFVs has seemingly little to no effect. The mere assistance in the assessment of the state seems not to be sufficient to improve market performance.

Concerning the trading behavior of in- and outsiders, we find that it differs at the beginning but converges during the course of the markets, indicating that that state information is revealed over time. In accordance with the predictions of the PI- and REmodels, we further find outsider limit buy/sell prices on average to be lower (higher) in the "good" ("bad") state compared to the limit buy/sell prices of insiders. As a result, outsiders on average hold less (more) assets in "good"-state ("bad"-state) markets. Thus, informed traders are able to earn superior profits. Depending on the state, they buy cheaply from or sell expensively to outsiders and thus capitalize their superior position.

With regard to elicited price expectations, we find forecasts and actual market prices to be highly correlated. The precision of forecasts, however, seems to be impeded by the presence of insiders while the provision of BFVs seems to have no impact on forecast quality.

We observe that the presence of insiders increases market efficiency. However, we have to be very cautious with this interpretation. We are not inclined to state that informational asymmetries are per se beneficial for market performance. In our experiment, the existence of insiders increases the information in the market. Increasing the level of information even more, we have conducted an additional experiment, in 
which we employed a standard SSW framework with a single state. Dividends again could take values of 10 ECU, 20 ECU, 40 ECU, or 80 ECU, however, with equal and fix probabilities of 25 percent, respectively. Traders did not face any uncertainty about the state, and were in a sense all insiders. These markets, again, hardly showed any bubbles. ${ }^{25}$ Additionally they exhibited with -0.078 a smaller average RD than all our other treatments with two possible states (accounted for the state) and with 0.180 also the smallest average RAD. ${ }^{26}$

Obviously, the more precise statement should be that increased information in a market tends to lead to more market efficiency. With regard to insiders we have to be aware of the fact that informational asymmetries in markets with insiders are not beneficial in all aspects. The higher market efficiency in our markets, where insiders were present and could trade on their information, is based on the expense of outsiders. Given the differences in the trading behavior, particularly in the beginning of the markets, insiders on average manage to shift their asset holdings to the detriment of outsiders. In addition, the presence of insiders seems to confuse outsiders given their significantly inferior market price forecast capability. Taken together, it is likely that deprived market participants in such trading environments would lose faith and trust in the securities' markets and possibly withdraw all or part of their capital, rendering the market less liquid.

Hence, to maintain the confidence in the fairness of financial markets, we rather support the position of proponents of insider trading regulation, requesting traders and other market agents possessing material nonpublic information to make reasonable efforts to achieve public dissemination of the relevant information on the broadest possible basis (CFA Institute Code of Ethics \& Standards of Professional Conduct CFA Institute 2010). We advocate all types of rules which are targeted towards faster and broader dissemination of information.

\section{Acknowledgement}

We thank Charles Noussair for very helpful comments as well as Till Vorlaufer for his excellent programming assistance. Financial support by Deutsche Forschungsgemeinschaft (DFG) GRK 1666 GlobalFood is gratefully acknowledged.

\footnotetext{
25 The general lack of bubbles might, besides the general difference of the structure of fundamentals, might be caused by the relatively small number of traders in our markets. This might decrease the incentives to speculate, in particular in combination with the call-auction trading mechanism, which tends to lead to a lower trading volume than continuous double-auction markets. However, Sutter et al. (2012) observed bubbles with the same number of traders per market and Haruvy et al. (2007) observed bubbles by using a call auction.

${ }^{26}$ Figure B. 1 in Appendix B shows the trajectory of individual market prices and Figure B. 2 the trajectory of the average price in this experiment.
} 


\section{References}

Ackert, L. F., B. K. Church. 1998. Information Dissemination and the Distribution of Wealth: Evidence from Experimental Asset Markets. Journal of Economic Behavior \& Organization 37(3) 357-371.

Ackert, L. F., B. K. Church, M. Shehata. 1997. Market Behavior in the Presence of Costly, Imperfect Information: Experimental Evidence. Journal of Economic Behavior \& Organization 33(1) 61-74.

Ang, J. S., T. Schwarz. 1985. Risk Aversion and Information Structure: An Experimental Study of Price Variability in the Securities Markets. The Journal of Finance 40(3) 825-844.

Aumann, R. J. 1976. Agreeing to Disagree. The Annals of Statistics 4(6) 1236-1239.

Bainbridge, S. M. 1998. Insider Trading: An Overview, SSRN 132529.

Ball, S. B., Charles A. Holt. 1998. Classroom Games - Speculation and Bubbles in an Asset Market. Journal of Economic Perspectives 12(1) 207-218.

Beck, N., J. N. Katz. 1995. What to do (and not to do) with Time-Series Cross-Section Data. The American Political Science Review 89(3) 634-647.

Bris, A. 2005. Do Insider Trading Laws Work? European Financial Management 11(3) 267-312.

Camerer, C. 1989. Bubbles and Fads in Asset Prices. Journal of Economic Surveys 3(1) 341.

Camerer, C. 1999. Behavioral Economics: Reunifying Psychology and Economics. Proceedings of the National Academy of Sciences 96(19) 10575-10577.

Camerer, C., G. Loewenstein, M. Weber. 1989. The Curse of Knowledge in Economic Settings: An Experimental Analysis. Journal of Political Economy 97(5) 1232-1254.

Camerer, C., K. Weigelt. 1991. Information Mirages in Experimental Asset Markets. The Journal of Business 64(4) 463-493.

CFA Institute. 2010. Standards of Practice Handbook. CFA Institute, Charlottesville, VA.

Chen, K.-Y., L. R. Fine, B. A. Huberman. 2004. Eliminating Public Knowledge Biases in Information-Aggregation Mechanisms. Management Science 50(7) 483-994.

Diba, B. T., H. I. Grossman. 1988a. Explosive Rational Bubbles in Stock Prices? The American Economic Review 78(3) 520-530.

Diba, B. T., H. I. Grossman. 1988b. The Theory of Rational Bubbles in Stock Prices. The Economic Journal 98(392) 746-754.

Dufwenberg, M., T. Lindqvist, E. Moore. 2005. Bubbles and Experience: An Experiment. The American Economic Review 95(5) 1731-1737.

Engelen, P.-J., L. Liedekerke. 2007. The Ethics of Insider Trading Revisited. Journal of Business Ethics 74(4) 497-507.

Fama, E. F. 1970. Efficient Capital Markets: A Review of Theory and Empirical Work. The Journal of Finance 25(2) 383-417. 
Fischbacher, U. 2007. z-Tree: Zurich Toolbox for Ready-made Economic Experiments. Experimental Economics 10(2) 171-178.

Fishman, M. J., K. M. Hagerty. 1992. Insider Trading and the Efficiency of Stock Prices. RAND Journal of Economics 23(1) 106-122.

Forsythe, R., T. R. Palfrey, C. R. Plott. 1982. Asset Valuation in an Experimental Market. Econometrica 50(3) 537-567.

Forsythe, R., T. R. Palfrey, C. R. Plott. 1984. Futures Markets and Informational Efficiency: A Laboratory Examination. The Journal of Finance 39(4) 955-981.

Friedman, D. 1993. Privileged Traders and Asset Market Efficiency: A Laboratory Study. The Journal of Financial and Quantitative Analysis 28(4) 515-534.

Gächter, S., E. Renner. 2010. The Effects of (Incentivized) Belief Elicitation in Public Goods Experiments. Experimental Economics 13(3) 364-377.

Greiner, B. 2004. The Online Recruitment System ORSEE 2.0 - A Guide for the Organization of Experiments in Economics. University of Cologne, Working Paper Series in Economics 10(23) 63-104.

Harrison, J. M., D. M. Kreps. 1978. Speculative Investor Behavior in a Stock Market with Heterogeneous Expectations. The Quarterly Journal of Economics 92(2) 323-336.

Haruvy, E., Y. Lahav, C. N. Noussair. 2007. Trader's Expectations in Asset Markets: Experimental Evidence. The American Economic Review 97(5) 1901-1920.

Holt, C. A., S. K. Laury. 2002. Risk Aversion and Incentive Effects. The American Economic Review 92(5) 1644-1655.

Hussam, R., D. P. Porter, V. L. Smith. 2008. Thar She Blows: Can Bubbles be Rekindled with Experienced Subjects? The American Economic Review 98(3) 924-937.

Jaffe, J. F. 1974. Special Information and Insider Trading. The Journal of Business 47(3) 410-428.

Jeng, L. A., Metrick Andrew, R. Zeckhauser. 2003. Estimating the Returns to Insider Trading: A Performance-Evaluation Perspective. Review of Economics and Statistics 85(2) 453-471.

Jordan, J. S. 1982. A Dynamic Model of Expectations Equilibrium. Journal of Economic Theory 28(2) 235-254.

Kahneman, D., A. Tversky. 1972. Subjective Probability: A Judgment of Representativeness. Cognitive Psychology 3(3) 430-454.

Keynes, J. M. 1936. The General Theory of Employment, Interest and Money, 2007th ed. Palgrave Macmillan.

King, R. R. 1991. Private Information Acquisition in Experimental Markets Prone to Bubble and Crash. The Journal of Financial Research 14(3) 197-206.

King, R. R., V. L. Smith, Williams Arlington W., M. van Boening. 1993. The Robustness of Bubbles and Crashes in Experimental Stock Markets. R. H. Day, P. Chen, eds. Nonlinear Dynamics and Evolutionary Economics. Oxford University Press, 183-200.

Lei, V., C. N. Noussair, C. R. Plott. 2001. Nonspeculative Bubbles in Experimental Asset Markets: Lack of Common Knowledge vs. Actual Irrationality. Econometrica 69(4) 831-859. 
Leland, H. E., D. H. Pyle. 1977. Informational Asymmetries, Financial Structure, and Financial Intermediation. The Journal of Finance 32(2) 371-387.

Liu, Y.-J. 1992. Auction Mechanisms and Information Structure: An Experimental Study of Information Aggregation in Securities Markets.

Lovaglia, M. J., J. W. Lucas, J. A. Houser, S. R. Thye, B. Markovsky. 1998. Status Processes and Mental Ability Test Scores. American Journal of Sociology 104(1) 195-228.

Manne, H. G. 1984. Insider Trading and Property Rights in New Information. Cato Journal 4 933-957.

McGee, R. W. 2008. Applying Ethics to Insider Trading. Journal of Business Ethics 77(2) 205-217.

Muth, J. F. 1961. Rational Expectations and the Theory of Price Movements. Econometrica 29(3) 315-335.

Noussair, C. N., C. R. Plott. 2008. Bubbles and Crashes in Experimental Asset Markets: Common Knowledge Failure. C. R. Plott, V. L. Smith, eds. Handbook of Experimental Economics Results, Volume 1. North Holland, 260-263.

Palan, S. 2009. Bubbles and Crashes in Experimental Asset Markets. Springer-Verlag, Berlin.

Palfrey, T. R., S. W. Wang. 2009. On Eliciting Beliefs in Strategic Games. Journal of Economic Behavior \& Organization 71(2) 98-109.

Plott, C. R., S. Sunder. 1982. Efficiency of Experimental Security Markets with Insider Information: An Application of Rational-Expectations Models. The Journal of Political Economy 90(4) 663-698.

Plott, C. R., S. Sunder. 1988. Rational Expectations and the Aggregation of Diverse Information in Laboratory Security Markets. Econometrica 56(5) 1085-1118.

Porter, D. P., V. L. Smith. 1994. Stock Market Bubbles in the Laboratory. Applied Mathematical Finance 1(2) 111-127.

Porter, D. P., V. L. Smith. 1995. Futures Contracting and Dividend Uncertainty in Experimental Asset Markets. The Journal of Business 68(4) 509-541.

Rabin, M., J. L. Schrag. 1999. First Impressions Matter: A Model of Confirmatory Bias. The Quarterly Journal of Economics 114(1) 37-82.

Romer, D. 1993. Rational Asset-Price Movements Without News. The American Economic Review 83(5) 1112-1130.

Shiller, R. J. 2003. From Efficient Markets Theory to Behavioral Finance. Journal of Economic Perspectives 17(1) 83-104.

Siegel, J. J. 2003. What Is an Asset Price Bubble? An Operational Definition. European Financial Management 9(1) 11-24.

Smith, V. L. 1976. Experimental Economics: Induced Value Theory. The American Economic Review, Papers and Proceedings 66(2) 274-279.

Smith, V. L., G. L. Suchanek, Arlington W. Williams. 1988. Bubbles, Crashes, and Endogenous Expectations in Experimental Spot Asset Markets. Econometrica 56(5) 1119-1151. 
Stöckl, T., J. Huber, M. Kirchler. 2010. Bubble Measures in Experimental Asset Markets. Experimental Economics 13(3) 284-298.

Sunder, S. 1992. Market for Information: Experimental Evidence. Journal of the Econometric Society 60(3) 667-695.

Sunder, S. 1995. Experimental Asset Markets: A Survey. John H. Kagel, A. E. Roth, eds. The Handbook of Experimental Economics. Princeton University Press, 445-500.

Sutter, M., J. Huber, M. Kirchler. 2012. Bubbles and Information: An Experiment. Management Science 58(2) 384-393.

Tirole, J. 1982. On the Possibility of Speculation under Rational Expectations. Econometrica 50(5) 1163-1181. 


\section{Appendix A}

\section{Additional Tables and Figures}

\section{$\underline{\text { Attitudes Toward Risk }}$}

Table A. 1: Risk-Test 1

\begin{tabular}{ccccc}
\hline $\begin{array}{c}\text { Decision } \\
\#\end{array}$ & Lottery A & Lottery B & $\begin{array}{c}\text { Expected } \\
\text { Payoff } \\
\text { Difference }\end{array}$ & $\begin{array}{c}\text { Risk Attitude } \\
\text { (\# safe } \\
\text { choices) }\end{array}$ \\
\hline 1 & $1 / 10$ of $50,9 / 10$ of 40 & $1 / 10$ of $96,9 / 10$ of 2 & 29.6 & -3 \\
2 & $2 / 10$ of $50,8 / 10$ of 40 & $2 / 10$ of $96,8 / 10$ of 2 & 21.2 & -2 \\
3 & $3 / 10$ of $50,7 / 10$ of 40 & $3 / 10$ of $96,7 / 10$ of 2 & 12.8 & -1 \\
4 & $4 / 10$ of $50,6 / 10$ of 40 & $4 / 10$ of $96,6 / 10$ of 2 & 4.4 & 0 \\
5 & $5 / 10$ of $50,5 / 10$ of 40 & $5 / 10$ of $96,5 / 10$ of 2 & -4.0 & 1 \\
6 & $6 / 10$ of $50,4 / 10$ of 40 & $6 / 10$ of $96,4 / 10$ of 2 & -12.4 & 2 \\
7 & $7 / 10$ of $50,3 / 10$ of 40 & $7 / 10$ of $96,3 / 10$ of 2 & -20.8 & 3 \\
8 & $8 / 10$ of $50,2 / 10$ of 40 & $8 / 10$ of $96,2 / 10$ of 2 & -29.2 & 4 \\
9 & $9 / 10$ of $50,1 / 10$ of 40 & $9 / 10$ of $96,1 / 10$ of 2 & -37.6 & 5 \\
10 & 1 of 50,0 of 40 & 1 of 96,0 of 2 & -46.0 & 5 \\
\hline
\end{tabular}

Notes: All payoffs are in ECUs. Lottery A is considered as the "safe" choice and Lottery B as the "risky" choice. $-5=$ extremely risk-loving, $-4=$ highly risk-loving, $-3=$ very risk-loving, $-2=$ risk-loving, $-1=$ slightly risk-loving, $0=$ risk-neutral, $1=$ slightly risk-averse, 2 risk-averse, $3=$ very risk-averse, $4=$ highly riskaverse, 5 = stay in bed.

Market $/$ subject mean $=1.750$, market maximum $($ minimum $)=3.000(0.500)$, subject maximum $($ minimum $)=5(-3)$. Spearman's rank correlation coefficient between the average risk attitude in one market and the market price in the $1^{\text {st }}$ period: $-0.0979, \mathrm{p}$-value $=0.5942$ (negative relationship expected).

Table A. 2: Risk-Test 2a

\begin{tabular}{ccccc}
\hline $\begin{array}{c}\text { Decision } \\
\text { No. }\end{array}$ & Lottery A & Safe Payoff & $\begin{array}{c}\text { Expected } \\
\text { Payoff } \\
\text { Difference }\end{array}$ & $\begin{array}{c}\text { Risk } \\
\text { Attitude } \\
\text { (\# safe } \\
\text { choices) }\end{array}$ \\
\hline 1 & & 20 & 29 & -5 \\
2 & & 25 & 24 & -4 \\
3 & Lottery A: & 30 & 19 & -3 \\
4 & 4/10 of 80, & 45 & 14 & -2 \\
5 & 3/10 of 40, & 45 & 9 & -1 \\
6 & 2/10 of 20, & 50 & -1 & 0 \\
7 & 1/10 of 10. & 55 & -6 & 1 \\
8 & & 60 & -11 & 3 \\
9 & & 65 & -16 & 4 \\
10 & & & -16 \\
\hline
\end{tabular}

Notes: All payoffs are in ECUs. $-5=$ extremely risk-loving, $-4=$ highly risk-loving, $-3=$ very risk-loving, -2 = risk-loving, -1 = slightly risk-loving, 0 = risk-neutral, 1 = slightly risk-averse, 2 risk-averse, 3 = very risk-averse, 4 = highly risk-averse, 5 = stay in bed. Market/subject mean $=-0.813$, market maximum (minimum) $=0.167(-2.167)$, subject maximum (minimum) $=4(-5)$. Spearman's rank correlation coefficient between the average risk attitude in one market and the market price in the $1^{\text {st }}$ period: $-0.0369, \mathrm{p}$ value $=0.8412$ (negative relationship expected) . 
Table A. 3: Risk-Test 2b

\begin{tabular}{ccccc}
\hline $\begin{array}{c}\text { Decision } \\
\#\end{array}$ & Lottery A & Safe Payoff & $\begin{array}{c}\text { Expected } \\
\text { Payoff } \\
\text { Difference }\end{array}$ & $\begin{array}{c}\text { Risk } \\
\text { Attitude } \\
\text { (\# safe } \\
\text { choices) }\end{array}$ \\
\hline 1 & & 5 & 21 & -4 \\
2 & 10 & 16 & -3 \\
3 & Lottery A: & 15 & 11 & -2 \\
4 & 1/10 of 80, & 20 & 6 & -1 \\
5 & 25 & 1 & 0 \\
6 & 2/10 of 40, & 30 & -4 & 1 \\
7 & 3/10 of 20, & 35 & -9 & 2 \\
8 & $4 / 10$ of 10. & 40 & -14 & 3 \\
9 & & 45 & -19 & 4 \\
10 & & 50 & -24 & 5 \\
\hline
\end{tabular}

Notes: All payoffs are in ECUs. $-5=$ extremely risk-loving, $-4=$ highly risk-loving, $-3=$ very risk-loving, $-2=$ risk-loving, $-1=$ slightly risk-loving, $0=$ risk-neutral, $1=$ slightly risk-averse, 2 risk-averse, 3 = very risk-averse, $4=$ highly risk-averse, $5=$ stay in bed. Market/subject mean $=0.427$, market maximum $($ minimum $)=1.500(-1.167)$, subject maximum $($ minimum $)=5(-4)$. Spearman's rank correlation coefficient between the average risk attitude in one market and the market price in the $1^{\text {st }}$ period: $0.1205, \mathrm{p}$ value $=0.5111$ (negative relationship expected).

Table A. 4: Ex-post Questionnaire Question - Attitude toward Risk

Question: Are you generally willing to take risks, or do you try to avoid risks?

Highly

risk-

averse

(0)

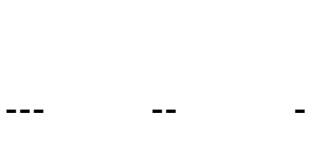

(5)
Highly

risk-

loving

(10)

Notes: Market/subject mean $=4.646$, market maximum (minimum) $=6.667$ (2.667), subject maximum (minimum) $=10(0)$. Spearman's rank correlation coefficient between the average risk attitude in one market and the market price in the $1^{\text {st }}$ period: $0.0956, p$-value $=0.6029$ (positive relationship expected). 
Table A. 5: First Period Comparisons of Insiders and Outsiders

\begin{tabular}{|c|c|c|c|c|c|c|}
\hline & \multicolumn{3}{|c|}{ Insider w/ Bayes ( $1^{\text {st }}$ Per.) } & \multicolumn{3}{|c|}{ Insider w/o Bayes ( 1 st Per.) } \\
\hline & + & - & p-value & + & - & p-value \\
\hline $\mathrm{p}^{\mathrm{D}}$ & 338.9 & 147.4 & .0397 & 524.3 & 340.0 & .0235 \\
\hline $\mathrm{p}^{\mathrm{S}}$ & 609.8 & 301.0 & .0541 & 761.0 & 607.5 & .0279 \\
\hline$q^{D}$ & 12.6 & 13.5 & .7116 & 12.4 & 5.3 & .0262 \\
\hline \multirow[t]{3}{*}{$\mathrm{q}^{\mathrm{s}}$} & 4.4 & 6.2 & .2245 & 8.6 & 4.4 & .0626 \\
\hline & \multicolumn{3}{|c|}{ Outsider w/ Bayes (1 $1^{\text {st }}$ Per.) } & \multicolumn{3}{|c|}{ Outsider w/o Bayes (1 $1^{\text {st }}$ Per.) } \\
\hline & + & - & $p$-value ${ }^{b}$ & + & - & p-value \\
\hline $\mathrm{p}^{\mathrm{D}}$ & 361.6 & 446.4 & .1257 & 290.7 & 355.7 & .3250 \\
\hline $\mathrm{p}^{\mathrm{S}}$ & 581.8 & 609.5 & .6807 & 517.1 & 602.8 & .6921 \\
\hline$q^{D}$ & 10.7 & 10.6 & .9293 & 13.3 & 8.8 & .4297 \\
\hline \multirow[t]{3}{*}{$q^{S}$} & 5.0 & 6.6 & .2744 & 6.1 & 5.6 & .6287 \\
\hline & \multicolumn{3}{|c|}{$\underline{w} /$ Bayes+ $\left(1^{\text {st }}\right.$ Per. $)$} & \multicolumn{3}{|c|}{$\underline{w} /$ Bayes- $\left(1^{\text {st }}\right.$ Per. $)$} \\
\hline & Insider & Outsider & $\mathrm{p}$-value & Insider & Outsider & p-value \\
\hline $\mathrm{p}^{\mathrm{D}}$ & 338.9 & 361.6 & .6968 & 147.4 & 446.4 & .0013 \\
\hline $\mathrm{p}^{\mathrm{S}}$ & 609.8 & 581.8 & .6100 & 301.0 & 609.5 & .0386 \\
\hline$q^{D}$ & 12.6 & 10.7 & .7947 & 13.5 & 10.6 & .8083 \\
\hline \multirow[t]{3}{*}{$\mathrm{q}^{\mathrm{S}}$} & 4.4 & 5.0 & .6733 & 6.2 & 6.6 & .9159 \\
\hline & \multicolumn{3}{|c|}{$\underline{\mathrm{w}} / \mathrm{o}$ Bayes+ $\left(1^{\text {st }}\right.$ Per. $)$} & \multicolumn{3}{|c|}{ w/o Bayes- $\left(1^{\text {st }}\right.$ Per. $)$} \\
\hline & Insider & Outsider & $\mathrm{p}$-value & Insider & Outsider & p-value \\
\hline $\mathrm{p}^{\mathrm{D}}$ & 524.3 & 290.7 & .0180 & 340.0 & 355.7 & .7830 \\
\hline $\mathrm{p}^{\mathrm{S}}$ & 761.0 & 517.1 & .1896 & 607.5 & 602.8 & .3560 \\
\hline$q^{D}$ & 12.4 & 13.3 & .5238 & 5.3 & 8.8 & .4484 \\
\hline$q^{S}$ & 8.6 & 6.1 & .0871 & 4.4 & 5.6 & .4296 \\
\hline
\end{tabular}

Notes: Mann-Whitney U test, two-sided: ${ }^{\mathrm{a}} N=16(8 / 8),{ }^{\mathrm{b}} N=32(16 / 16),{ }^{\mathrm{c}} N=24(8 / 16)$. 
Table A. 6: Profit and Prediction Earnings of Insiders and Outsiders

\begin{tabular}{|c|c|c|c|c|c|c|}
\hline & \multicolumn{3}{|c|}{ Insider+ } & \multicolumn{3}{|c|}{ Insider- } \\
\hline & $\begin{array}{c}\mathrm{w} / \\
\text { Bayes }\end{array}$ & $\begin{array}{c}\mathrm{w} / \mathrm{o} \\
\text { Bayes }\end{array}$ & $\mathrm{p}$-value & $\begin{array}{c}\mathrm{w} / \\
\text { Bayes }\end{array}$ & $\begin{array}{c}\mathrm{w} / \mathrm{o} \\
\text { Bayes }\end{array}$ & p-value \\
\hline Profita & 7568 & 8962 & .0929 & 4369 & 4483 & .6744 \\
\hline \multirow[t]{3}{*}{ Pred. Earnings ${ }^{a}$} & 133.1 & 172.9 & .0460 & 137.3 & 136.3 & .4005 \\
\hline & \multicolumn{3}{|c|}{ Outsider+ } & \multicolumn{3}{|c|}{ Outsider- } \\
\hline & $\begin{array}{c}\text { w/ } \\
\text { Bayes }\end{array}$ & $\begin{array}{c}\text { w/o } \\
\text { Bayes } \\
\end{array}$ & p-value & $\begin{array}{c}\text { w/ } \\
\text { Bayes }\end{array}$ & $\begin{array}{c}\mathrm{w} / \mathrm{o} \\
\text { Bayes }\end{array}$ & p-value \\
\hline Profit ${ }^{b}$ & 7183 & 6527 & .2582 & 4315 & 4235 & .6242 \\
\hline \multirow[t]{3}{*}{ Pred. Earnings ${ }^{\mathrm{b}}$} & 100.3 & 121.5 & .4397 & 131.3 & 108.2 & .5216 \\
\hline & \multicolumn{3}{|c|}{$\underline{\mathrm{w} / \text { Bayest }}$} & \multicolumn{3}{|c|}{ w/ Bayes- } \\
\hline & Insider & Outsider & $\mathrm{p}$-value & Insider & Outsider & p-value \\
\hline Profitc $^{c}$ & 7568 & 7183 & .3913 & 4369 & 4315 & .9025 \\
\hline \multirow[t]{3}{*}{ Pred. Earnings ${ }^{c}$} & 133.1 & 100.3 & .3272 & 137.3 & 131.3 & .8303 \\
\hline & \multicolumn{3}{|c|}{ w/o Bayes+ } & \multicolumn{3}{|c|}{ w/o Bayes- } \\
\hline & Insider & Outsider & $\mathrm{p}$-value & Insider & Outsider & $\mathrm{p}$-value \\
\hline Profitc & 8962 & 6527 & .0059 & 4483 & 4235 & .3913 \\
\hline Pred. Earnings ${ }^{c}$ & 172.9 & 121.5 & .1500 & 136.3 & 108.2 & .2439 \\
\hline
\end{tabular}


Figure A. 1: Average Limit Buy Order Prices
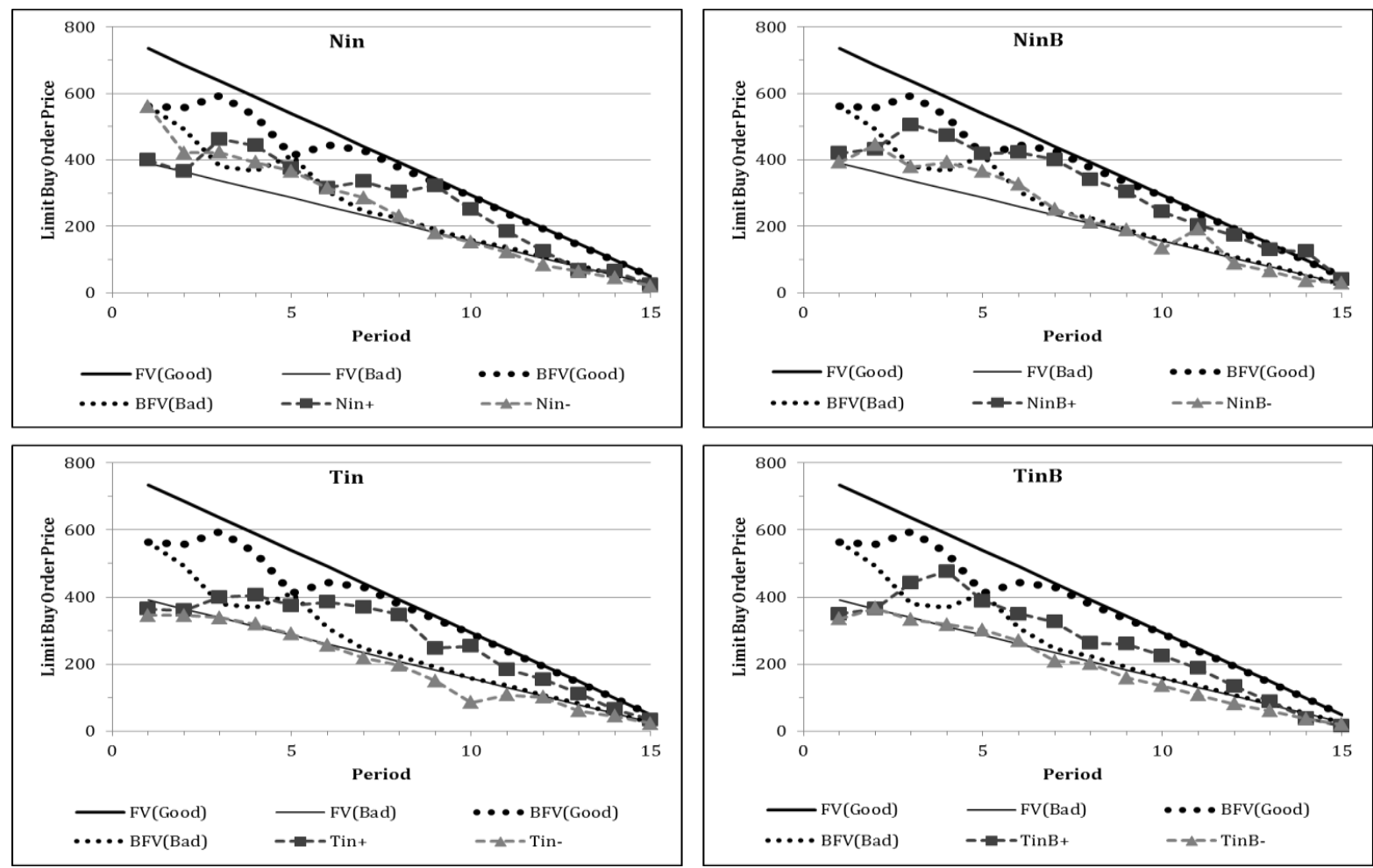

Figure A. 2: Average Limit Sell Order Prices
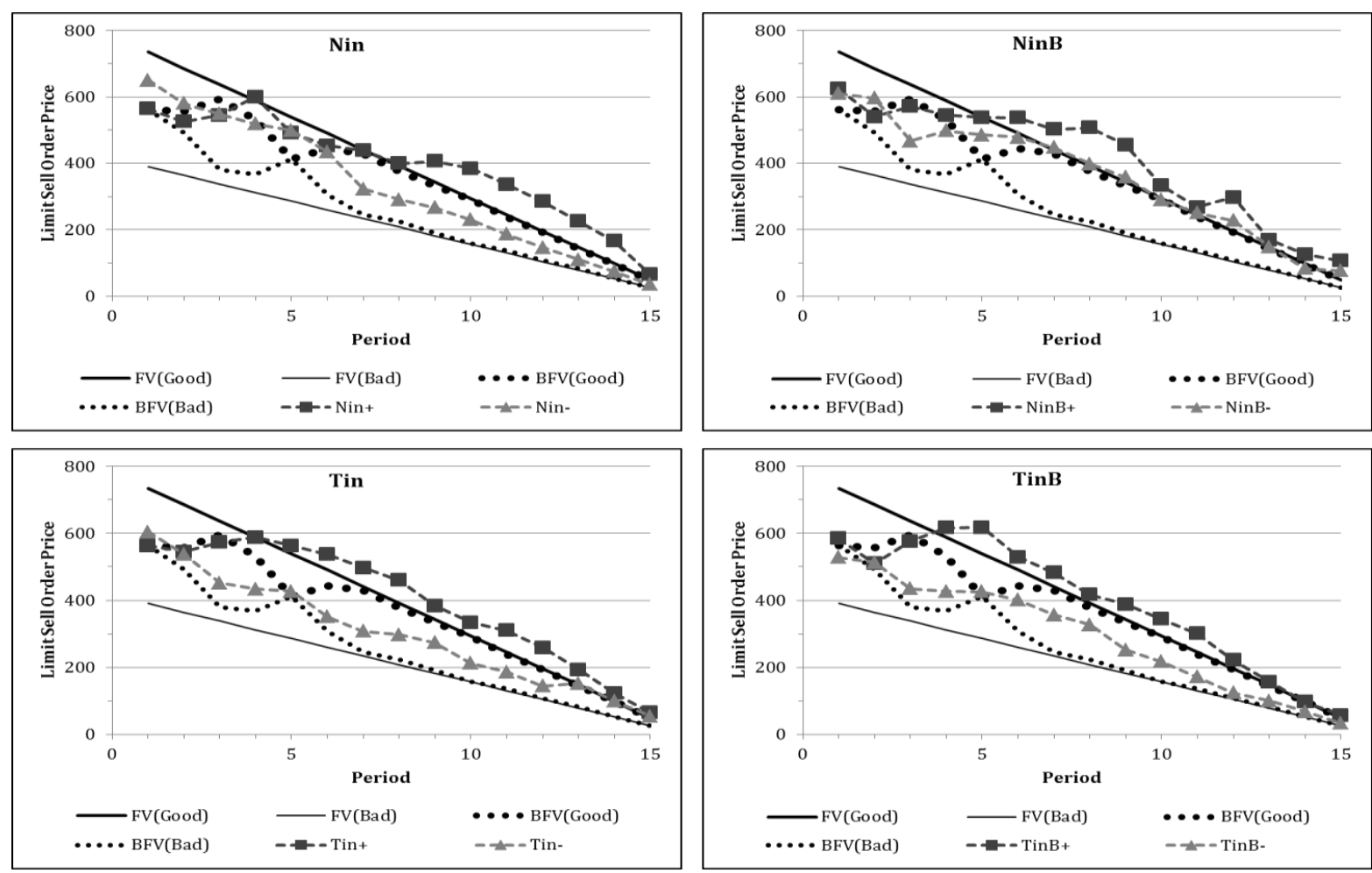


\section{Beliefs}

Figure A. 3: Standard Deviations of Predicted Market Prices
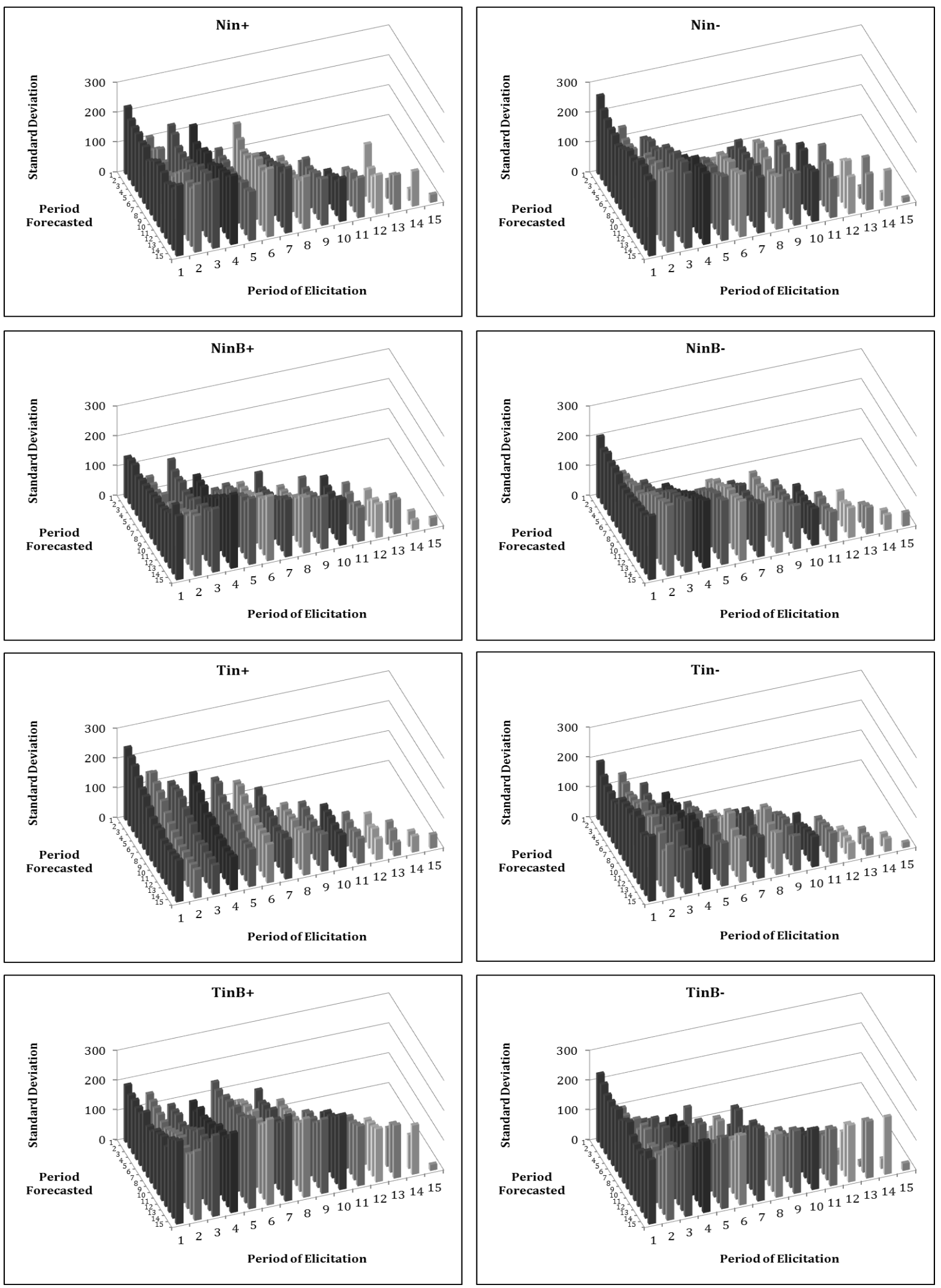
Appendix B

Results of Additional Experiments with Known Fundamentals (SSW Framework)

Figure B. 1: Individual Market Prices in the SSW Framework

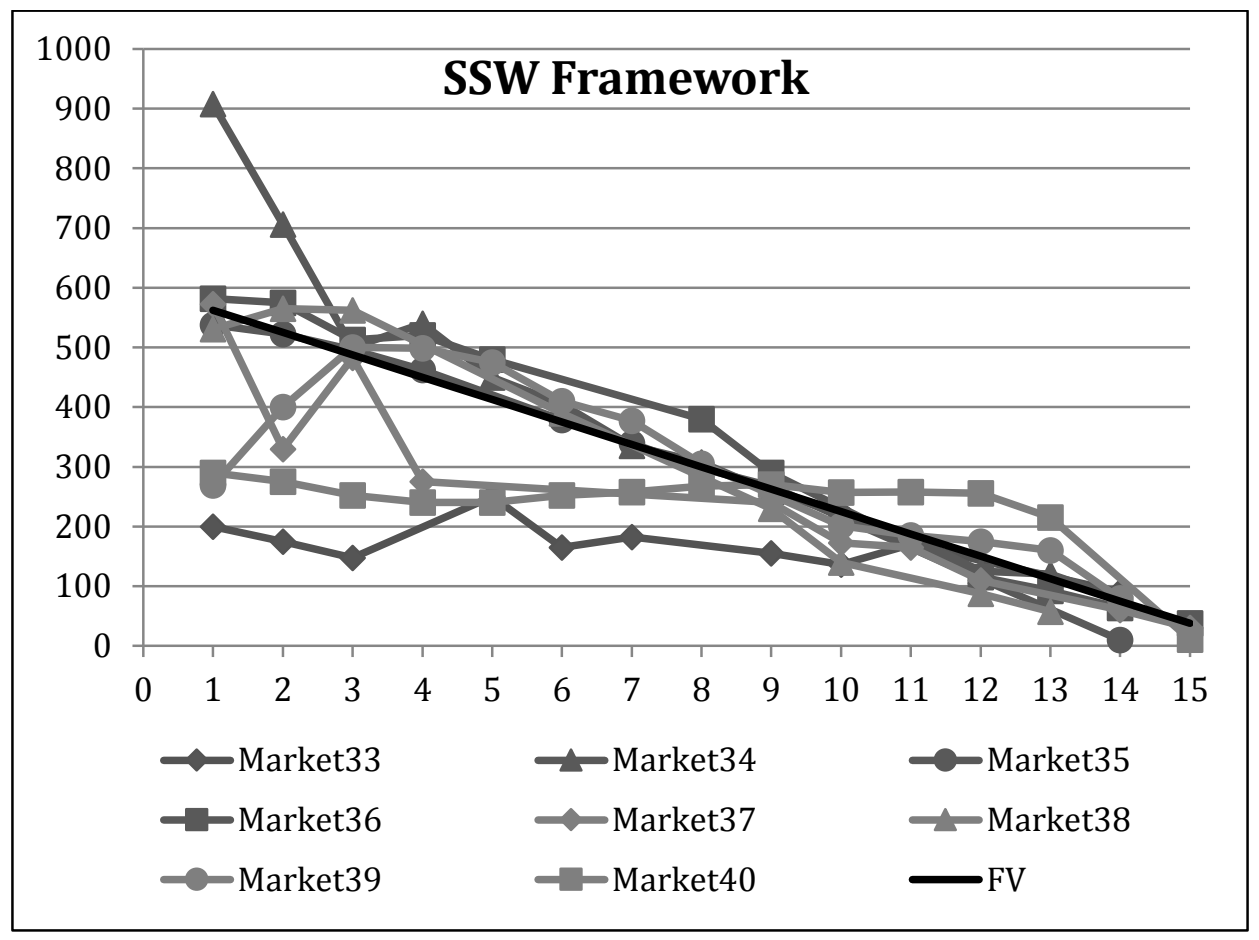

Figure B. 2: Average Market Price in the SSW Framework

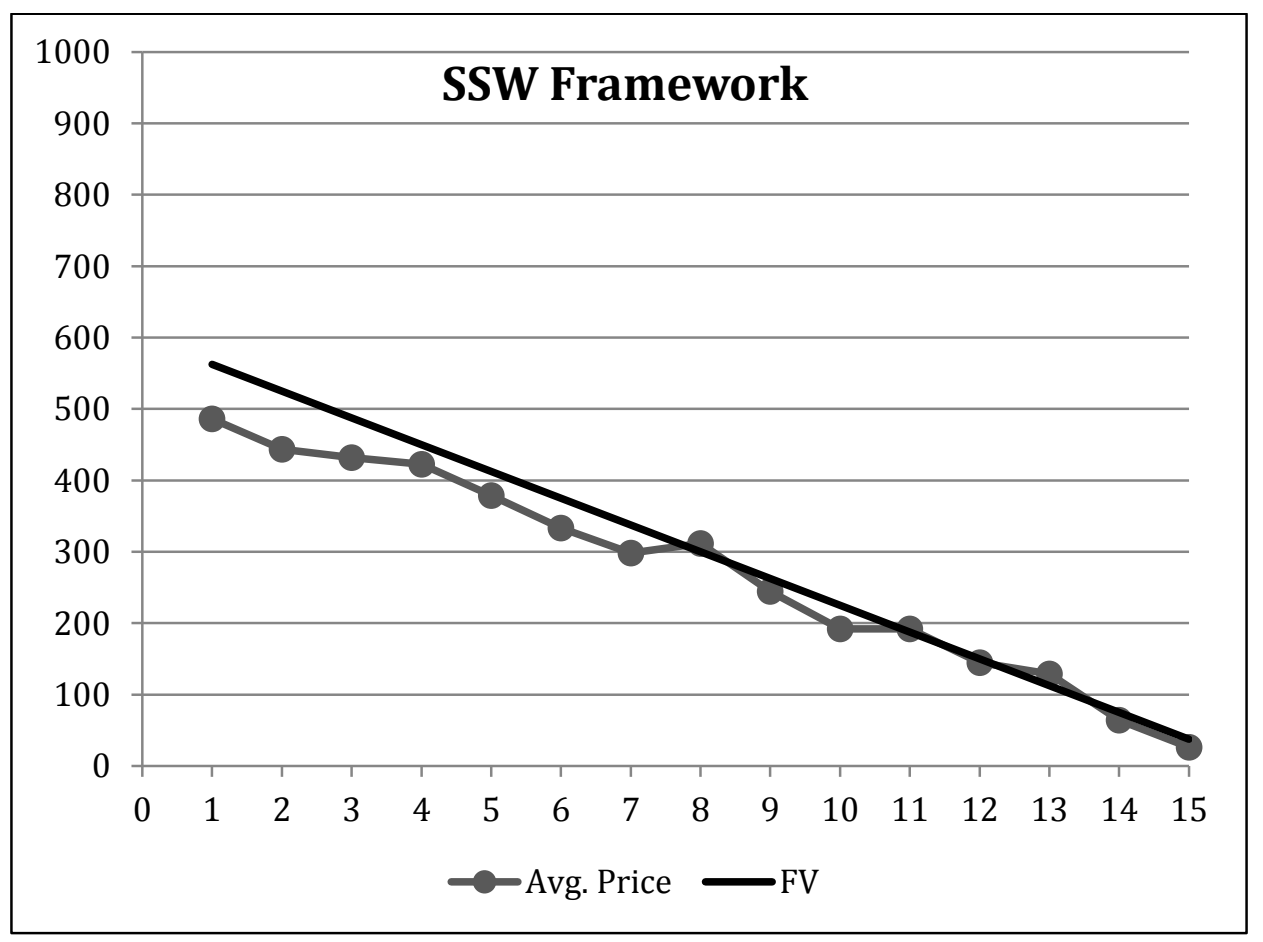




\section{Appendix C}

\section{EXPERIMENTAL INSTRUCTIONS (RISK TESTS)}

Welcome! You participate in an experiment that consists of two parts. In Part I of the experiment, you first take part in a decision experiment in which you can earn money. How much you earn depends, in Part I, only on your personal decisions. In Part II, your earnings will also depend on the choices of others. Each participant makes its decisions in isolation from the others on her/his computer. We ask you not to talk to other participants.

\section{PART I}

Part I of the experiment consists of three tasks. In Task 1 you have to make 10 decisions, first. In each you must choose between two options, lottery X or lottery Y. Each lottery involves two payments, for which there are different probabilities of occurrence, in each case. The payoffs are given in a fictitious currency ECU (experimental currency units). At the end of Part I, the computer will select among your 10 decisions randomly one, for which you are paid according to your selected option. The resulting ECUs are converted according to a fixed exchange rate in $€$.

In Task $2 \mathrm{~A}$ and $2 \mathrm{~B}$, you have to make 10 decisions each, choosing between a lottery and a safe payment (in ECU). At the end of Part I, the computer will select from among these choices randomly one, each, for which you are paid in $€$ according to your selected option, taking into account the exchange rate.

\section{AVAILABLE INFORMATION}

A calculator is available at the right side of each decision screen which you can open via a small calculator icon. Once you have made your decisions in all three tasks, you will receive your results on the screen including your payment in € for Part I of the experiment.

\section{PAYMenT}

Your proceeds (in ECU) from the three tasks of Part I are converted into $€$, whereat each ECU is worth €0.005. You will also receive a compensation for your appearance. The payout is conducted individually and anonymously at the end of the experiment.

In order to start the experiment, you need to click on the $<$ Next $>$ button. After completion of Part I, we ask you to stay at your place in the cabin and wait for further instructions for Part II of the experiment. 


\section{EXPERIMENTAL INSTRUCTIONS (TINB)}

In Part II, the main part of the experiment, you will participate in a market experiment in which you can still earn money. How much you earn depends, in this part, on your decisions and, unlike Part I, also on the decisions of other participants. Each participant makes its decisions in isolation from the others on her/his computer. We ask you not to talk to other participants.

\section{PART II}

You now participate in a market which runs 15 trading periods. At the beginning you will be randomly matched with five other persons to build a group of six, in which you remain throughout the 15 trading periods. You will not know the identity of your group members at any time, though.

In this part, you assume the role of a trader on a stock market, for assets of a single type. On this market, you have the opportunity to submit a buy and / or a sell offer in each of the 15 trading periods. However, you are not obliged to.

At the beginning of the 15 periods, each group member is endowed with 10 assets and an initial trading capital of 10,000 ECU. This initial trading capital has to be repaid at the end of the experiment in full, again!

\section{The Value of AN AsSeT}

Each asset has a lifespan of 15 trading periods. The so-called fundamental value of an asset is determined in each of the 15 periods as the sum of the, for all assets identical, dividends to be accrued in the future. After the last dividend payment at the end of the last period the asset is worthless. The dividend for an asset is randomly determined in each period by the computer and can take a value of 10 ECU, 20 ECU, 40 ECU or 80 ECU.

There are two possible "states" with respect to the asset, State 1 ("good" state) and State 2 ("bad" state). Each state has the same probability of 50\%. Given these probabilities, the computer randomly selects one of the two states before the first trading period. This state (State 1 or State 2) withstands for the total market duration of 15 trading periods.

Two randomly selected participants per group of six participants, whose identity remains secret, will be informed at the beginning of the market which state has actually been chosen and applies to all participants during the entire duration of the market. The other participants receive no information about the actually chosen state. The randomly drawn state determines the probabilities with which each of the possible values of the dividends of $10 \mathrm{GE}, 20 \mathrm{GE}, 40 \mathrm{GE}$ or 80 GE are drawn. These probabilities and the expected dividend of one asset are presented in Table 1 for the two states.

Since, in the two states, the probabilities of the possible dividend values and thus the expected dividend per period of an asset are different, also the fundamentals of an asset will develop in different ways over the course of the market. Table 2 shows the computation of the fundamental values in the periods 1 to 15 for the two possible states. 
Table 1

\begin{tabular}{ccc}
\hline & $\begin{array}{c}\text { State 1 ("good") } \\
\text { [50\%] }\end{array}$ & $\begin{array}{c}\text { State 2 (“bad") } \\
\text { [50\%] }\end{array}$ \\
\hline & $10 \mathrm{ECU}[10 \%]$ & $10 \mathrm{ECU}[40 \%]$ \\
Possible Dividends & $20 \mathrm{ECU}[20 \%]$ & $20 \mathrm{ECU}[30 \%]$ \\
[Probabilities] & $40 \mathrm{ECU}[30 \%]$ & $40 \mathrm{ECU}[20 \%]$ \\
& $80 \mathrm{ECU}[40 \%]$ & $80 \mathrm{ECU}[10 \%]$ \\
\hline $\begin{array}{c}\text { Expected Dividend } \\
\text { of an Asset per Period }\end{array}$ & $49 \mathrm{ECU}$ & $26 \mathrm{ECU}$ \\
\hline
\end{tabular}

Table 2

\begin{tabular}{cccccc}
\hline & \multicolumn{5}{c}{ Fundamental Values (in ECU) } \\
\hline Period & $\begin{array}{c}\text { State 1 } \\
\text { ("good") } \\
{[\mathbf{5 0 \% ]}}\end{array}$ & $\begin{array}{c}\text { Cond. } \\
\text { Prob. for }\end{array}$ & $\begin{array}{c}\text { State } 2 \\
\text { (“bad") }\end{array}$ & $\begin{array}{c}\text { Cond. } \\
\text { Prob. for } \\
\text { State } 1\end{array}$ & $\begin{array}{c}\text { Expected Value } \\
\text { according to Bayes }\end{array}$ \\
\hline $\mathbf{1}$ & $735(=15 \times 49)$ & 0.5 & $390(=15 \times 26)$ & 0.5 & $\begin{array}{c}562.5 \\
\text { State } 1\end{array}$ \\
$\mathbf{2}$ & $686(=14 \times 49)$ & $\mathrm{p}_{1,2}$ & $364(=14 \times 26)$ & $\mathrm{p}_{2,2}$ & $\mathrm{p}_{1,2} \times 686+\mathrm{p}_{2,2} \times 364$ \\
$\mathbf{3}$ & $637(=13 \times 49)$ & $\mathrm{p}_{1,3}$ & $338(=13 \times 26)$ & $\mathrm{p}_{2,3}$ & $\mathrm{p}_{1,3} \times 637+\mathrm{p}_{2,3} \times 338$ \\
$\mathbf{4}$ & $588(=12 \times 49)$ & $\mathrm{p}_{1,4}$ & $312(=12 \times 26)$ & $\mathrm{p}_{2,4}$ & $\mathrm{p}_{1,4} \times 588+\mathrm{p}_{2,4} \times 312$ \\
$\mathbf{5}$ & $539(=11 \times 49)$ & $\mathrm{p}_{1,5}$ & $286(=11 \times 26)$ & $\mathrm{p}_{2,5}$ & $\mathrm{p}_{1,5} \times 539+\mathrm{p}_{2,5} \times 286$ \\
$\mathbf{6}$ & $490(=10 \times 49)$ & $\mathrm{p}_{1,6}$ & $260(=10 \times 26)$ & $\mathrm{p}_{2,6}$ & $\mathrm{p}_{1,6} \times 490+\mathrm{p}_{2,6} \times 260$ \\
$\mathbf{7}$ & $441(=9 \times 49)$ & $\mathrm{p}_{1,7}$ & $234(=9 \times 26)$ & $\mathrm{p}_{2,7}$ & $\mathrm{p}_{1,7} \times 441+\mathrm{p}_{2,7} \times 234$ \\
$\mathbf{8}$ & $392(=8 \times 49)$ & $\mathrm{p}_{1,8}$ & $208(=8 \times 26)$ & $\mathrm{p}_{2,8}$ & $\mathrm{p}_{1,8} \times 392+\mathrm{p}_{2,8} \times 208$ \\
$\mathbf{9}$ & $343(=7 \times 49)$ & $\mathrm{p}_{1,9}$ & $182(=7 \times 26)$ & $\mathrm{p}_{2,9}$ & $\mathrm{p}_{1,9} \times 343+\mathrm{p}_{2,8} \times 182$ \\
$\mathbf{1 0}$ & $294(=6 \times 49)$ & $\mathrm{p}_{1,10}$ & $156(=6 \times 26)$ & $\mathrm{p}_{2,10}$ & $\mathrm{p}_{1,10} \times 294+\mathrm{p}_{2,10 \times 156}$ \\
$\mathbf{1 1}$ & $245(=5 \times 49)$ & $\mathrm{p}_{1,11}$ & $130(=5 \times 26)$ & $\mathrm{p}_{2,11}$ & $\mathrm{p}_{1,11 \times 245+\mathrm{p}_{2,11} \times 130}$ \\
$\mathbf{1 2}$ & $196(=4 \times 49)$ & $\mathrm{p}_{1,12}$ & $104(=4 \times 26)$ & $\mathrm{p}_{2,12}$ & $\mathrm{p}_{1,12 \times 196+\mathrm{p}_{2,12} \times 104}$ \\
$\mathbf{1 3}$ & $147(=3 \times 49)$ & $\mathrm{p}_{1,13}$ & $78(=3 \times 26)$ & $\mathrm{p}_{2,13}$ & $\mathrm{p}_{1,13} \times 147+\mathrm{p}_{2,13} \times 78$ \\
$\mathbf{1 4}$ & $98(=2 \times 49)$ & $\mathrm{p}_{1,14}$ & $52(=2 \times 26)$ & $\mathrm{p}_{2,14}$ & $\mathrm{p}_{1,14 \times 98+\mathrm{p}_{2,14} \times 52}$ \\
$\mathbf{1 5}$ & $49(=1 \times 49)$ & $\mathrm{p}_{1,15}$ & $26(=1 \times 26)$ & $\mathrm{p}_{2,15}$ & $\mathrm{p}_{1,15} \times 49+\mathrm{p}_{2,15} \times 26$ \\
\hline
\end{tabular}


Since, in the game, you are not necessarily informed about which state has actually been drawn, you may only know the initial probability of $50 \%$ for each state, you are provided at the beginning of each period with recalculated probabilities for the two states according to the socalled Bayesian method. These so-called conditional probabilities for the states take into account the, up to that time, randomly drawn dividends. Because the conditional probabilities cannot be specified in advance, they are denoted in Table 2 with $p_{i, j}$. Thereby, $i \in\{1,2\}$ denotes the state and $j \in\{2, \ldots, 15\}$ denotes the period. In addition to the recalculated conditional probabilities you are provided, at the beginning of each period, with a fundamental value which is adapted to these conditional probabilities (fundamental value according to Bayes) on your screen.

\section{DECISIONS}

Before you can submit your buy and sell offers for the assets in each trading period, you are asked to forecast the resulting asset price in the market for all future periods. This market price is determined and announced to you at the end of each period. In particular, you enter in each period $t \epsilon\{1, \ldots, 15\}$ a total of $(16-t)$ forecasts for the future periods. Because you can rethink your forecasts in each period, you have to submit for each period $t$ a total of $t$ forecasts in the course of the market. Depending on the forecast accuracy of your forecasts you receive a payment (in ECU) after each period which was predicted. Table 3 gives an overview of the payments depending on the quality of forecasts. These payments can be received for each period $t$ a maximum of $t$ times. With the <Tabulator $>$ button you can switch the entry fields for your decisions. All entries are completed by clicking on the $<$ Submit Forecasts! $>$ button.

Tabelle 3:

\begin{tabular}{cc} 
Accuracy of the Forecast & $\begin{array}{c}\text { Payment for each Correct } \\
\text { Forecast }\end{array}$ \\
\hline Within $\pm 10 \%$ of the actual market price & 5 ECU \\
Within $\pm 10-20 \%$ of the actual market price & $2 \mathrm{ECU}$ \\
Within $\pm 20-30 \%$ of the actual market price & $1 \mathrm{ECU}$ \\
\hline
\end{tabular}

Trading in each period takes place as follows. Each trading period lasts a maximum of 240 seconds. In the first 120 seconds, you first have the opportunity to submit an offer to buy by entering a "limit buy price" and the corresponding "limit buy quantity" in the appropriate fields on the screen.

The limit buy price is the price you are willing to pay at most per asset. This means you buy at this or any lower price which is established on the market. Please enter in addition to your limit buy price your corresponding limit purchase quantity of assets you want to buy at a price lower than or equal to your limit buy price. If only a smaller amount of assets is available on the market for you, you get this smaller amount. In extreme cases, it is also possible that you get no assets. If you do not want to buy at any price but want just to keep your asset inventory, leave the entry fields empty.

Please confirm your entries by clicking on the button <Confirm Buying Decision!>. Subsequently you switch to the screen for the submission of your selling offer. 
In the second 120 seconds you have then the opportunity to submit an offer to sell, by entering a "limit sell price" and the corresponding "limit sell quantity" in the appropriate fields on the screen.

The limit sell price is the price you want to have at least per asset. This means you sell at this or any higher price which is established on the market. Please enter in addition to your limit sell price your corresponding limit sell quantity of assets you want to sell at a price higher than or equal to your limit sell price. If there is only a lower demand for your assets on the market, you sell this smaller amount. In extreme cases, it is also possible that you sell no assets. If you do not want to sell at any price but want just to keep your asset inventory, leave the entry fields empty.

Please confirm your entries by clicking on the button <Confirm Selling Decision!>. When all participants have completed their decision to sell, the experiment continues. All buy and all sell offers aggregated, respectively. Out of this, the market price and the corresponding trading volume (the total quantity traded) are determined. All individual transactions that are possible under these conditions are conducted. If no transactions can take place, there is no market price. In this case, we denote the market price with 0 .

Transactions take place as long as there are dealers who want to sell at a lower or the same price than dealers are willing to pay. For the determination of the market price and trading volume all bids are aggregated, from the highest to the lowest bid, into a falling demand curve in price, and all selling offers are aggregated, from the lowest to the highest selling offer, into an increasing supply curve in price. The intersection of these two curves determines the (maximum possible) trading volume. The market price is determined as the average of the smallest limit buy price and the highest limit sell price for which a transaction just comes about.

Please note that your inventory of assets and trading capital changes through trade after each period. The selling of assets reduces the asset and increases the trading capital inventory. The buying of assets increases the asset and reduces the trading capital inventory. In addition, the dividend income, of the assets held by you at the end of each period, increases the trading capital.

When choosing your buying and selling offers, you must ensure that they are permissible. If you trade, you firstly can never sell more assets than you have in your own asset inventory in this period, secondly never buy more assets, as is permitted by the available sum of the asset holdings of the other market participants in your group and thirdly never buy more assets at a certain price, as is permitted by your trading capital in this period. Fourthly, you must note that your limit sell price, at which you wish to sell assets, must be higher than your limit buy price, at which you wish to buy assets. Possible prices that may be entered are all integer numbers between 1 and 1500, as long as none of the rules above is violated. If you make an entry that violates these rules, this will be automatically indicated on the screen and you have to revise your input. However in this case, you also have the opportunity to continue without entering an offer by leaving the entry fields empty.

Should you have not verified your buying and/or selling decision during the respective 120 seconds, the (possibly) until then entered decisions are not taken into account, i.e., you would not buy or sell anything in the respective decision stage! 


\section{AvaILABLE INFORMATION}

A calculator is available at the right side of each decision screen, which you can open via a small calculator icon. Additionally, you are provided in each period, in all decision stages, with all relevant information via a summary table on the screen. Just click on the button $<$ Show Results of Previous Periods $>$ which is located in the middle at the bottom of the screen. To return from this summary screen back into the respective decision stage, you have to click on the button $<$ Back to...>, respectively. Furthermore, an overview of the results of the just completed period is displayed after each period on the screen.

\section{PAYMENT}

Your relevant income for the payout (in ECU) in Part II of the experiment is determined by your trading capital at the end of the last period minus the initial trading capital. The relevant income for the payout is calculated alternatively as the sum of your individual period profits. The period profit is calculated as follows:

$\begin{aligned} \text { Period profit }= & \begin{array}{l}\text { Your asset holdings at the end of the period } \times \text { Dividend per Asset } \\ \text { in this period (= dividend income) }\end{array} \\ + & \begin{array}{l}\text { Proceeds from the disposal of assets in this period } \\ -\end{array} \\ & \begin{array}{l}\text { Expenditures for purchased assets in this period } \\ \text { Remuneration for the forecast(s) of the market price in this period }\end{array}\end{aligned}$

Your relevant income for the payout (in ECU) from Part II is converted into €, whereat each ECU is worth $€ 0.003$. In addition, you will receive your payout from Part I and a show-up fee of $€ 3$. If your trading capital at the end of the last period of part II is not sufficient for the repayment of the initial trading capital, your relevant income for the payout in Part II is negative. This negative payment is deducted from your payout from Part I and your show-up fee. However, you cannot suffer a real loss, i.e., your minimum payout is zero. The payout is conducted individually and anonymously at the end of the experiment.

We ask you now to go to the computer with your participation number. There you have to click on <Continue>. You then will be given on your screen a number of questions regarding these instructions. If you have any questions please address yourself to the experimenter. Only when all participants have correctly answered all questions, the experiment starts. 


\section{Screenshots}

\begin{tabular}{|c|c|c|c|c|c|c|c|c|c|}
\hline \multirow[b]{2}{*}{ Zeile } & \multicolumn{5}{|c|}{ Lotterie X } & \multicolumn{4}{|c|}{ Lotterie Y } \\
\hline & $\begin{array}{l}\text { Auszahlung } \\
\text { (in GE) }\end{array}$ & $\begin{array}{l}\text { Wahrscheinlichkeit } \\
\text { der Auszahlung }\end{array}$ & $\begin{array}{l}\text { Auszahlung } \\
\text { (in GE) }\end{array}$ & $\begin{array}{l}\text { Wahrscheinlichkeit } \\
\text { der Auszahlung }\end{array}$ & Ihre Entscheidung & $\begin{array}{l}\text { Auszahlung } \\
\text { (in GE) }\end{array}$ & $\begin{array}{l}\text { Waarsscheinlichkeit } \\
\text { der Auszahlung }\end{array}$ & $\begin{array}{l}\text { Auszahlung } \\
\text { (in GE) }\end{array}$ & $\begin{array}{l}\text { Wahrscheinlichkeit } \\
\text { der Auszahlung }\end{array}$ \\
\hline 1 & 50 & $10 \%$ & 40 & $90 \%$ & Lotterie X $\subset \subset$ Lotterie $Y$ & 96 & $10 \%$ & 2 & $90 \%$ \\
\hline 2 & 50 & $20 \%$ & 40 & $80 \%$ & Lotterie $X \subset \subset$ Lotterie $Y$ & 96 & $20 \%$ & 2 & $80 \%$ \\
\hline 3 & 50 & $30 \%$ & 40 & $70 \%$ & Lotterie $X \subset \subset$ Lotterie $Y$ & 96 & $30 \%$ & 2 & $70 \%$ \\
\hline 4 & 50 & $40 \%$ & 40 & $60 \%$ & Lotterie $X \subset \subset$ Lotterie $Y$ & 96 & $40 \%$ & 2 & $60 \%$ \\
\hline 5 & 50 & $50 \%$ & 40 & $50 \%$ & Lotterie $X \subset \subset$ Lotterie $Y$ & 96 & $50 \%$ & 2 & $50 \%$ \\
\hline 6 & 50 & $60 \%$ & 40 & $40 \%$ & Lotterie $X \subset \subset$ Lotterie $Y$ & 96 & $60 \%$ & 2 & $40 \%$ \\
\hline 7 & 50 & $70 \%$ & 40 & $30 \%$ & Lotterie $X \subset \subset$ Lotterie $Y$ & 96 & $70 \%$ & 2 & $30 \%$ \\
\hline 8 & 50 & $80 \%$ & 40 & $20 \%$ & Lotterie $X \subset \subset$ Lotterie $Y$ & 96 & $80 \%$ & 2 & $20 \%$ \\
\hline 9 & 50 & $90 \%$ & 40 & $10 \%$ & Lotterie $X \subset \subset$ Lotterie $Y$ & 96 & $90 \%$ & 2 & $10 \%$ \\
\hline 10 & 50 & $100 \%$ & 40 & $0 \%$ & Lotterie $X \subset \subset$ Lotterie $Y$ & 96 & $100 \%$ & 2 & $0 \%$ \\
\hline
\end{tabular}

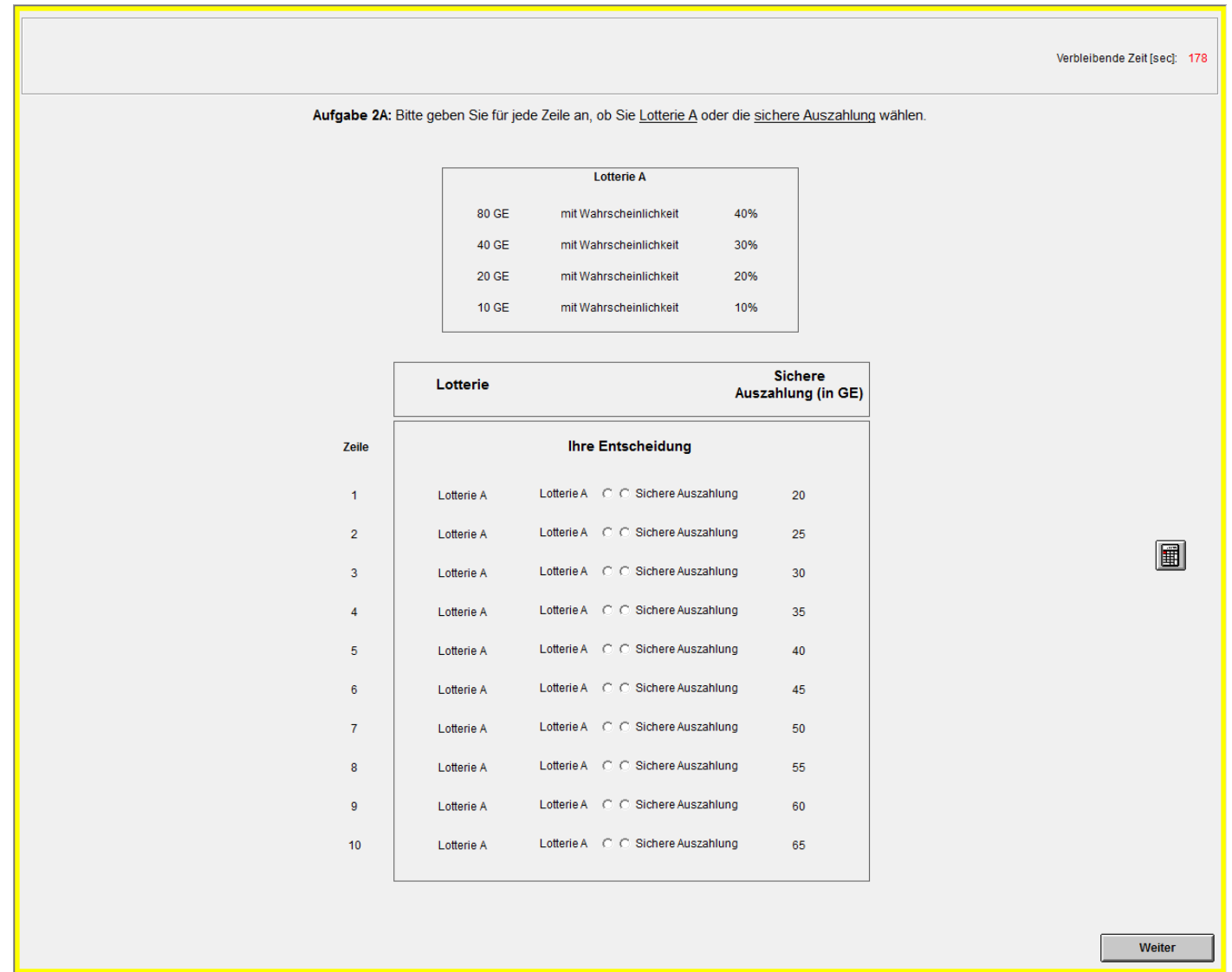


Aufgabe 2B: Bitte geben Sie für jede Zeile an, ob Sie Lotterie B oder die sichere Auszahlung wählen.

\begin{tabular}{|c|c|c|c|c|}
\hline & & & Lotterie B & \\
\hline & $80 \mathrm{GE}$ & mit Wa & hrscheinlichkeit & $10 \%$ \\
\hline & $40 \mathrm{GE}$ & mit Wa & hrs cheinlichkeit & $20 \%$ \\
\hline & $20 \mathrm{GE}$ & mit Wa & hrscheinlichkeit & $30 \%$ \\
\hline & $10 \mathrm{GE}$ & mit Wa & hrscheinlichkeit & $40 \%$ \\
\hline & Lotterie & & & $\begin{array}{l}\text { Sichere } \\
\text { Auszahlung (in GE) }\end{array}$ \\
\hline Zeile & & Ihre & Entscheidung & \\
\hline 1 & Lotterie B & Lotterie B & $\subset \subset$ sichere Auszahlung & 5 \\
\hline 2 & Lotterie B & Lotterie B & $\subset \subset$ sichere Auszahlung & 10 \\
\hline 3 & Lotterie B & Lotterie B & $\subset \subset$ Sichere Auszahlung & 15 \\
\hline 4 & Lotterie B & Lotterie B & $\subset \subset$ Sichere Auszanlung & 20 \\
\hline 5 & Lotterie B & Lotterie B & $\subset \subset$ sichere Auszahlung & 25 \\
\hline 6 & Lotterie B & Lotterie B & $\subset \subset$ Sichere Auszanlung & 30 \\
\hline 7 & Lotterie B & Lotterie B & $\subset \subset$ Sichere Auszanlung & 35 \\
\hline 8 & Lotterie B & Lotterie B & $r<$ sichere Auszahlung & 40 \\
\hline 9 & Lotterie B & Lotterie B & $\subset \subset$ sichere Auszahlung & 45 \\
\hline 10 & Lotterie B & Lotterie B & $\subset \subset$ Sichere Auszahlung & 50 \\
\hline
\end{tabular}

\section{Ergebnisse für Teil I}

Ergebnis aus Aufgabe 1:

Die zufällig für die Auszahlung ausgewähtte Zeile Inr Erros in GE aus Aufgabe 1

Ergebnis aus Aufgabe 2A:

Die zưfallig für die Auszahlung ausgewähte Zeile Die von Ihnen gewählte Atternative in dieser Zeile Lotterie Ihr Erlös in GE aus Aưgabe 2A

Ergebnis aus Aufgabe 2B:

Die zưällig für die Auszahlung ausgewähte Zeile Die von Innen gewähite Alternative in cieser Zeile Ihr Erlös in GE aus Aufgabe 2B $\quad 10$

Itre Auszahlung in Euro aus Ihren Entscheidungen in Teill 

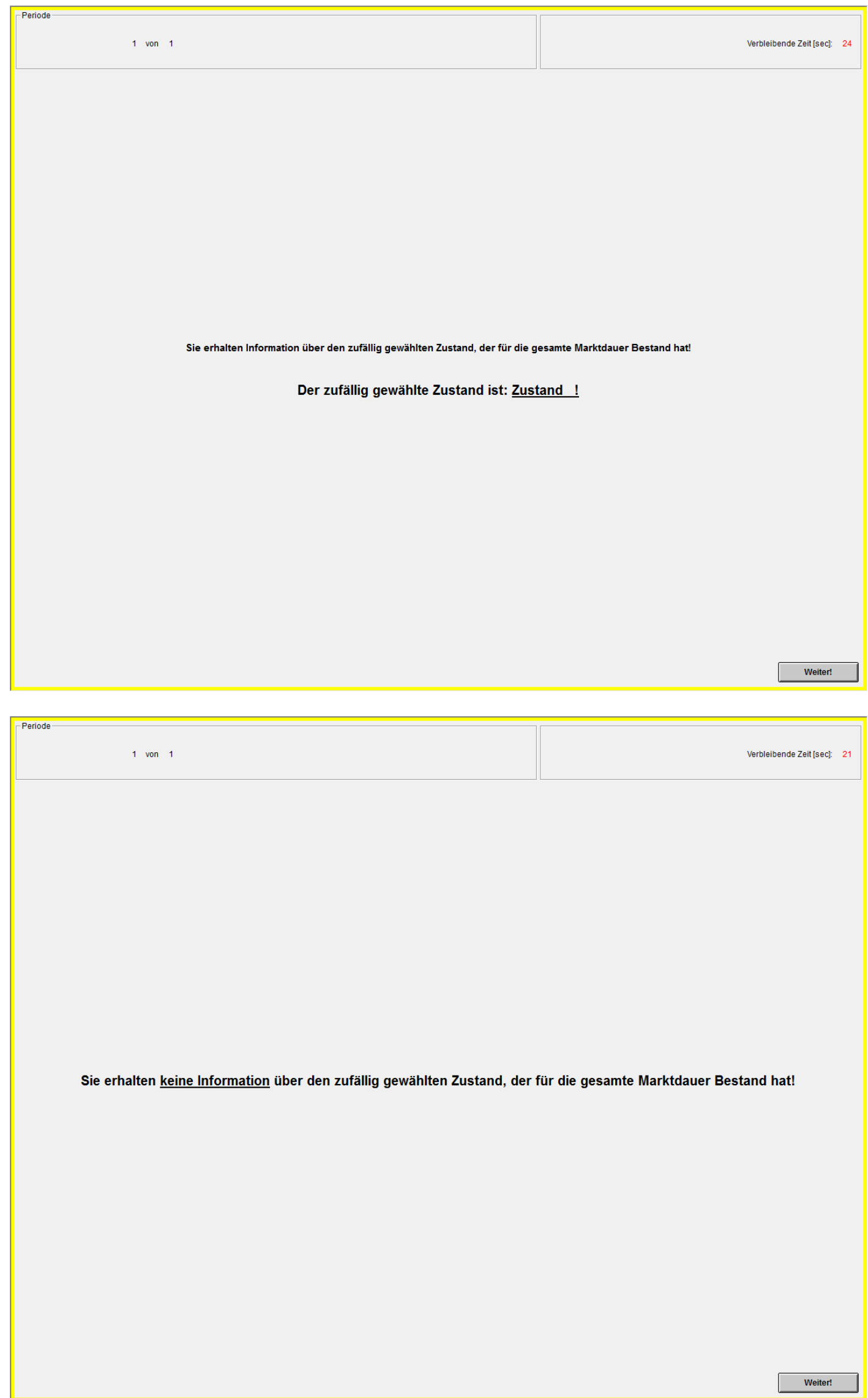

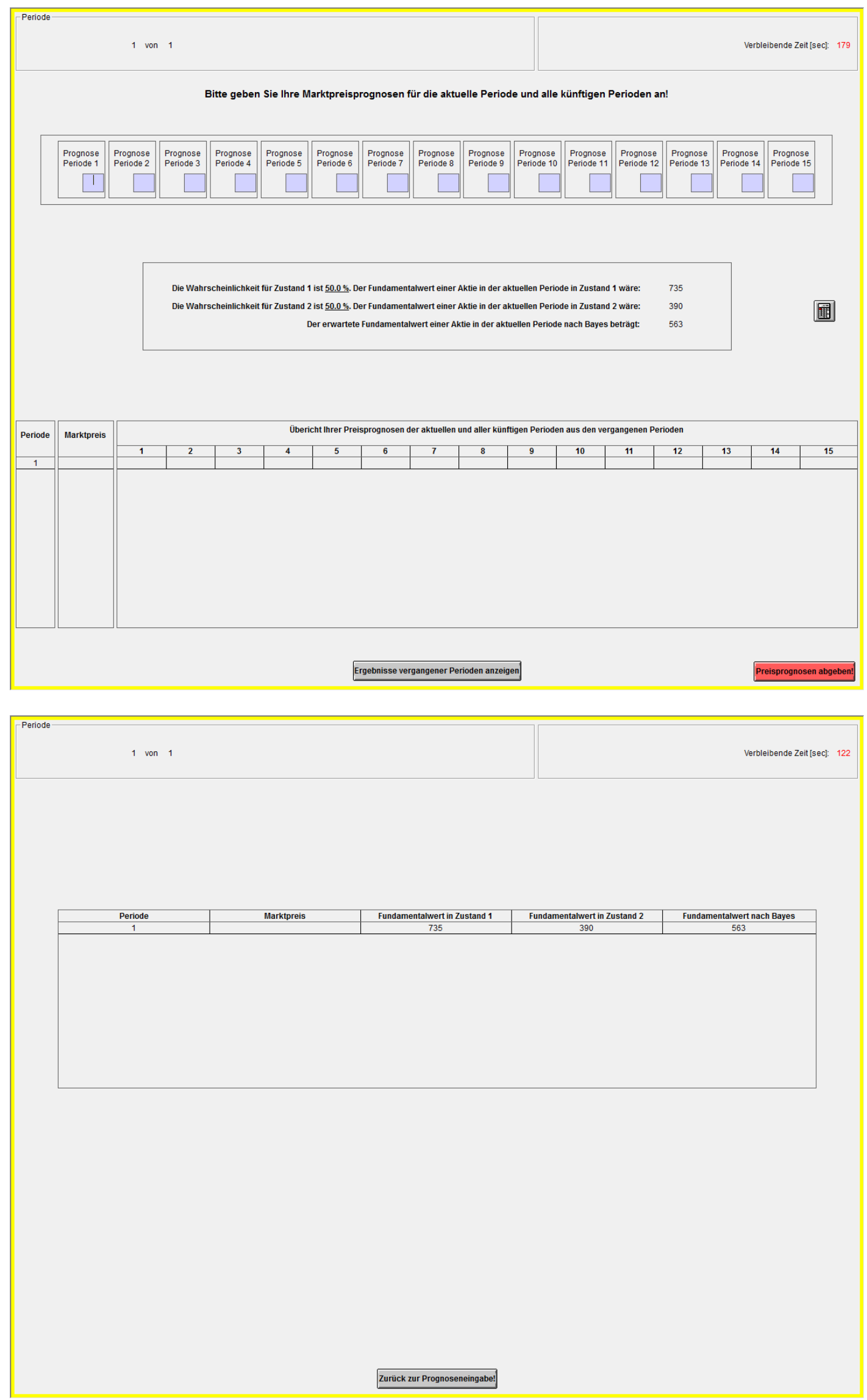

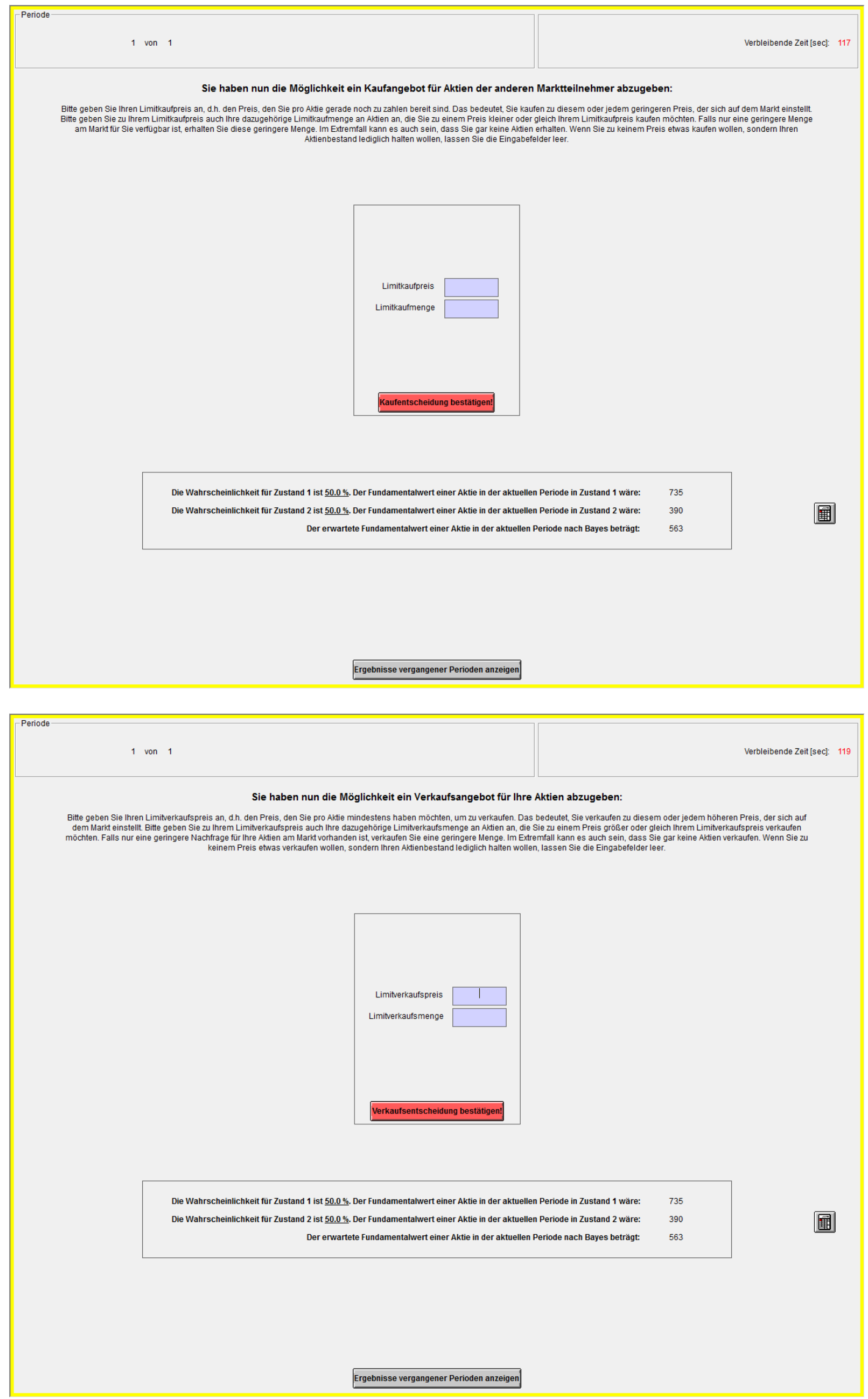

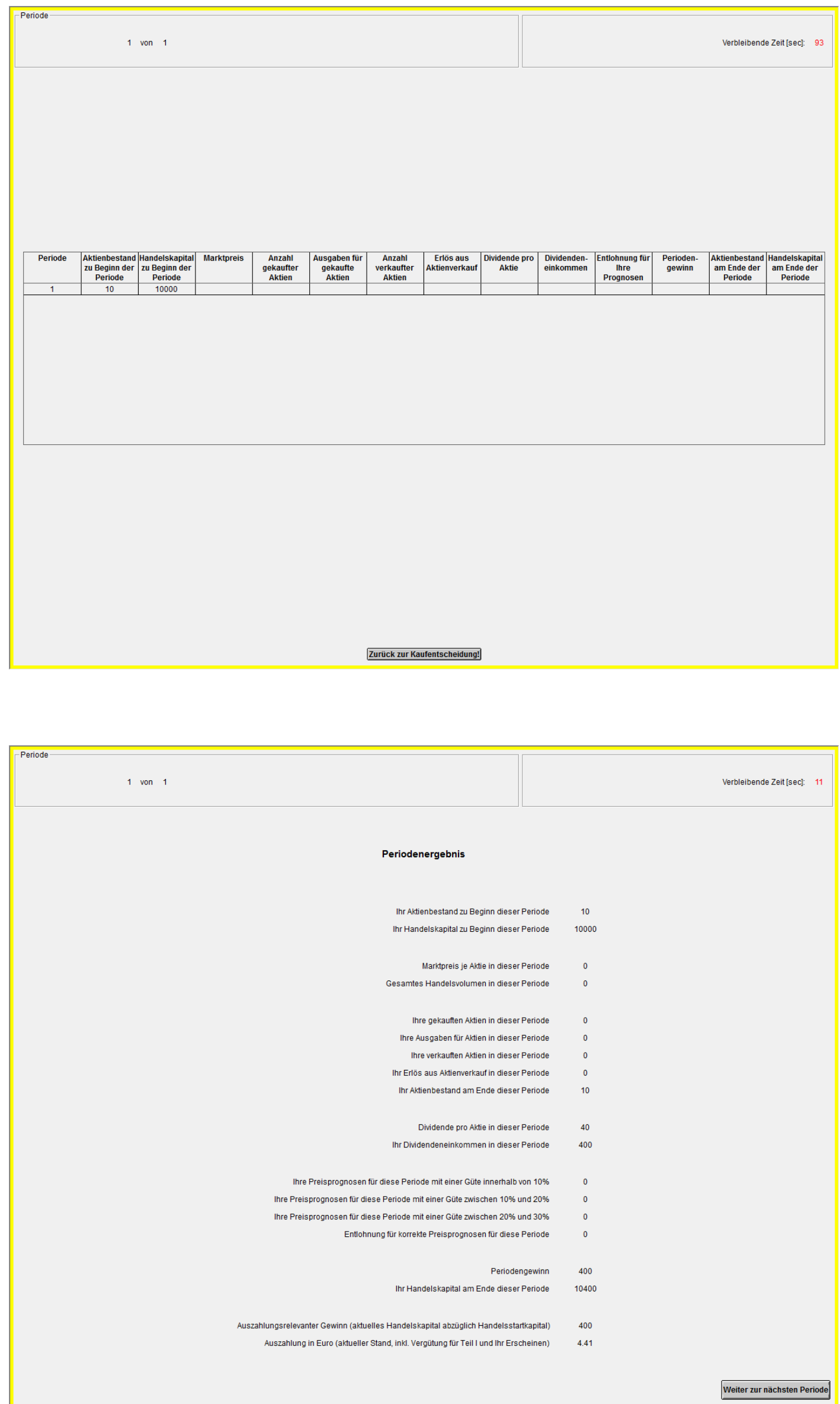